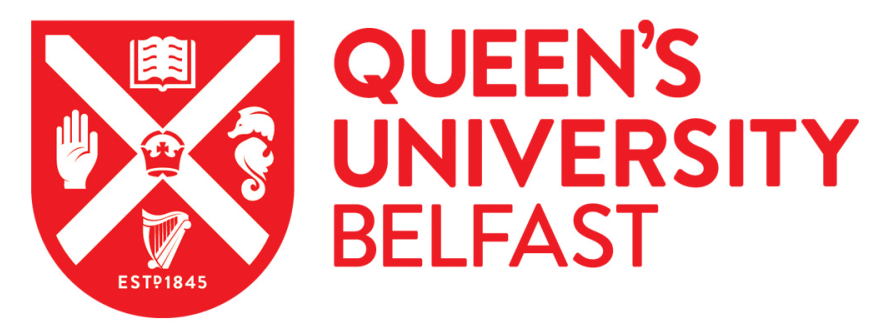

\title{
Determination of the mode I crack resistance curve of polymer composites using the size-effect law
}

Catalanotti, G., Arteiro, A., Hayati, M., \& Camanho, P. P. (2014). Determination of the mode I crack resistance curve of polymer composites using the size-effect law. Engineering Fracture Mechanics, 118, 49-65.

https://doi.org/10.1016/j.engfracmech.2013.10.021

\section{Published in:}

Engineering Fracture Mechanics

Document Version:

Peer reviewed version

Queen's University Belfast - Research Portal:

Link to publication record in Queen's University Belfast Research Portal

\section{Publisher rights}

(c) Elsevier B. V. 2013. This manuscript version is made available under the CC-BY-NC-ND 4.0 license

http://creativecommons.org/licenses/by-nc-nd/4.0/, which permits distribution and reproduction for non-commercial purposes, provided the author and source are cited.

\section{General rights}

Copyright for the publications made accessible via the Queen's University Belfast Research Portal is retained by the author(s) and / or other copyright owners and it is a condition of accessing these publications that users recognise and abide by the legal requirements associated with these rights.

Take down policy

The Research Portal is Queen's institutional repository that provides access to Queen's research output. Every effort has been made to ensure that content in the Research Portal does not infringe any person's rights, or applicable UK laws. If you discover content in the Research Portal that you believe breaches copyright or violates any law, please contact openaccess@qub.ac.uk. 


\title{
Determination of the mode I crack resistance curve of polymer composites using the size-effect law
}

\author{
G. Catalanotti *, A. Arteiro, M. Hayati, P.P. Camanho \\ DEMec, Faculdade de Engenharia, Universidade do Porto, Rua Dr. Roberto Frias, \\ 4200-465, Porto, Portugal
}

\begin{abstract}
This paper presents a new method to measure the crack resistance curve associated with the longitudinal failure of polymer composites reinforced by unidirectional fibres. Rather than using compact tension test specimens, the identification of the size-effect law of double edge notched specimens is used to obtain the crack resistance curve. Special emphasis is placed on the appropriate calculation of the stress intensity factor of the specimens when using quasi-isotropic or cross-ply laminates. For this purpose, both analytical closed-form solutions and numerical methods are investigated. Four different carbon-epoxy material systems, T800/M21, IM7/8552, T700/AR-2527, and T700/ACE are tested and the corresponding size effect laws and R-curves are measured. A good correlation between the crack resistance curve obtained using the size effect law and that previously measured for one of the material systems using the compact tension test is obtained. The highest value of the longitudinal fracture toughness was obtained for the T800/M21 material.
\end{abstract}

Key words:

A. Fibre reinforced materials, B. Fracture mechanics, C. R-curves, D. Size effects

* Corresponding author. Tel: +351 22508 1716/1049; Fax: +351 225081315.

Email address: giuseppe.catalanotti@fe.up.pt (G. Catalanotti). 


\section{Nomenclature}

$a, a_{0} \quad$ crack length, initial value of the crack length

$A, C \quad$ fitting parameter used in the linear regression I fit

$A, C \quad$ fitting parameter used in the linear regression II fit

É equivalent modulus

$f \quad$ correction factor for the dimensionality of the specimen

$\mathcal{G}_{I} \quad$ energy release rate in mode I

$h \quad$ thickness of the laminate

$h_{0}, h_{90}$ thickness of the $0^{\circ}$ and $90^{\circ}$ plies, respectively

$\mathcal{K}_{I} \quad$ stress intensity factor

$l \quad$ half of the length of the specimen

$l_{e} \quad$ size of the element

$l_{f p z} \quad$ length of fracture process zone

$M, N \quad$ fitting parameter used in the bilogarithmic regression fit

$P \quad$ applied load.

$P_{u} \quad$ peak load

$\mathcal{R} \quad$ R-curve

$\mathcal{R}_{0}, \mathcal{R}_{90}$ R-curves for the $0^{\circ}$ ply an $90^{\circ}$ ply, respectively

$\mathcal{R}_{s s} \quad$ steady-state value of fracture toughness

$\mathcal{R}_{0 s s} \quad$ steady-state value of the fracture toughness of the $0^{\circ}$ ply

$s_{l m} \quad$ components of the compliance matrix computed in the $x_{1}-x_{2}$ coordinate system

$t \quad$ thickness of the specimen

$u_{l} \quad$ nodal displacement

$w \quad$ half of the width of the specimen

$x_{1}, x_{2} \quad$ preferred axes of the material

$Y_{m} \quad$ nodal load

$\alpha, \alpha_{0} \quad$ shape parameter, initial value of the shape parameter

$\beta, \gamma \quad$ parameters used in the R-curve fit

$\Delta a \quad$ crack increment

$\epsilon \quad$ error

$\zeta \quad$ elastic parameter

$\kappa \quad$ correction factor

$\kappa_{0} \quad$ correction factor $\kappa$ for $\alpha=\alpha_{0}$

$\kappa_{0} \quad$ derivative, with respect to $\alpha$, of the correction factor $\kappa$ for $\alpha=\alpha_{0}$

$\boldsymbol{K}$ matrix for the polynomial fitting of $\kappa$

$\lambda \quad$ elastic parameter

$\xi \quad$ shape-parameter

$\rho \quad$ elastic parameter

$\sigma \quad$ remote stress

$\sigma_{u} \quad$ ultimate nominal stress

$\hat{\sigma}_{u} \quad$ corrected value of the ultimate stress

$\phi \quad$ correction factor for an infinitely long specimen

$\Phi \quad$ matrix for the polynomial fitting of $\phi$

$\chi \quad$ correction factor for the orthotropy of the material

$\psi \quad$ correction factor for the length of the specimen

$\Psi \quad$ matrix for the polynomial fitting of $\psi$

Avg. $\quad$ average value

SD standard deviation 


\section{Introduction}

2 The most recent analysis methods that predict fracture of polymer composite materials require not only the value of the fracture toughness, but also its relation with the increment of the crack length, i.e., the crack resistance curve. Taking the thickness of the individual ply as the representative length scale it is possible to formulate 'mesomodels' that account for both delamination (interlaminar cracking) and ply failure mechanisms (intralaminar cracking) [1-3]. The softening constitutive relation that simulates longitudinal failure, where the fracture plane is approximately perpendicular to the fibre direction, requires the fracture toughness to regularize the numerical solution [3]; however, the crack resistance curve must also be measured to identify the different regions of the softening constitutive relation so that the failure mechanisms acting at the crack tip and along the wake of the crack are properly accounted for [4].

Recently, Finite Fracture Mechanics models that use the laminate thickness as the representative length-scale have been developed to predict fracture of multidirectional composite laminates in the presence of stress concentrations [5-7]. These methods are typically used for the preliminary design and optimization of composite structures, and are based on the simultaneous fulfilment of a stress-based criterion, which requires a stress allowable, and of an energy based criterion, which requires the fracture toughness [5-7] or the crack resistance curve [8].

Based on the above observations, it becomes apparent that reliable test methods for the measurement of the intralaminar fracture toughness ${ }^{1}$ of composite laminates and of the corresponding crack resistance curve (R-curve) are required. While a strong emphasis has been placed on the use of compact tension test specimens [9], recent results have shown that using the current geometry of the compact tension test specimen it is not possible to measure the fracture toughness of modern resin systems that result in high values of the fracture toughness [10]. For example, in previous attempts to measure the fracture toughness of cross-ply Hexcel's T800/M21 carbon-epoxy laminates using the geometry proposed in [9] the region of the specimen subjected to compressive stresses buckled [10]; such an elastic instability renders the test results

$\overline{1}$ Two different types of failure mechanisms are usually considered in fibre reinforced composites: interlaminar, when crack propagation occurs between the plies of the laminate (i.e. delamination), and intralaminar, when crack propagation occurs within the individual plies of the laminate. 
where $\mathcal{K}_{I}$ and $E$ are respectively the stress intensity factor and the equivalent modulus. The equivalent modulus reads:

$$
\dot{E}=\left(s_{11} s_{22} \frac{1+\rho}{2}\right)^{-1 / 2} \lambda^{1 / 4}
$$

meaningless.

Therefore, the objective of this paper is to develop a new methodology to obtain the R-curve of polymer composite laminates reinforced by unidirectional fibres. The main idea put forward here, which follows Bažant's seminal work [11], is to relate the size effect law with the crack resistance curve of the composite material. The general overview of such relation is presented in section 2. Section 3 describes the experiments that were performed in three different types of carbon-epoxy composite laminates and presents the corresponding R-curves. The conclusions and suggestions for future work are presented in section 4 .

\section{Analytical Model}

\subsection{Overview}

Consider the geometry shown in Figure 1. The width of the specimen is equal to $2 w$ and $a_{0}$ is the initial crack length. The length of the specimen is $2 l$.

[Fig. 1 about here.]

In a two-dimensional orthotropic body, taking $x_{1}$ and $x_{2}$ as the preferred axes of the material (see Figure 1), the mode I component of the energy release rate for crack propagation in the $x_{1}$-direction, $\mathcal{G}_{I}$, reads [12]:

$$
\mathcal{G}_{I}=\frac{1}{\dot{E}} \mathcal{K}_{I}^{2}
$$

where $s_{l m}$ are the components of the compliance matrix calculated in the $x_{1}$ $x_{2}$ coordinate system, and $\lambda$ and $\rho$ are two dimensionless elastic parameters defined as:

$$
\lambda=\frac{s_{11}}{s_{22}}, \quad \rho=\frac{2 s_{12}+s_{66}}{2 \sqrt{s_{11} s_{22}}}
$$


The stress intensity factor in equation (1) is a function of $\rho$, of the remote stress $\sigma$, and of the shape and size of the specimen. Using the orthotropic rescaling technique $[12,13]$, the stress intensity factor of a notched bar can be written as:

$$
\mathcal{K}_{I}=\sigma \sqrt{w} \kappa(\alpha, \rho, \zeta)
$$

where $\zeta=\lambda^{-1 / 4} \xi, \alpha=a / w$ and $\xi=w / L$ are the shape-parameters, and $\kappa$ is the correction factor that depends on the geometry and orthotropy of the material.

Replacing (4) in (1) the energy release rate reads:

$$
\mathcal{G}_{I}=\frac{1}{\dot{E}} w \sigma^{2} \kappa^{2}=\frac{1}{4 w \dot{E}}\left(\frac{P \kappa}{t}\right)^{2}
$$

where $t$ is the thickness of the specimen and $P$ is the applied load. Assuming that $\kappa$ is an increasing function of the crack length (the specimen has a positive geometry), the size effect method can be used to measure the fracture toughness of the material [11]. Equation (5) can be re-written as:

$$
\mathcal{G}_{I}(\Delta a)=\frac{P^{2}}{4 w t^{2} E} \kappa^{2}\left(\alpha_{0}+\frac{\Delta a}{w}, \rho, \zeta\right)
$$

where $\alpha_{0}$ is the initial value of the shape parameter, $\alpha_{0}=a_{0} / w$. For different sizes, $w_{n}$, the crack driving-force curves $\mathcal{G}_{I}$ corresponding to the peak loads, $P_{u n}$, are tangent to R-curve, and this fact can be used to measure the Rcurve, $\mathcal{R}$. Mathematically the peak load, $P_{u}$, or the ultimate nominal stress, $\sigma_{u}=P_{u} /(2 w t)$, can be obtained from the following system of equations:

$$
\left\{\begin{array}{l}
\mathcal{G}_{I}(\Delta a)=\mathcal{R}(\Delta a) \\
\frac{\partial \mathcal{G}_{I}(\Delta a)}{\partial \Delta a}=\frac{\partial \mathcal{R}(\Delta a)}{\partial \Delta a}
\end{array}\right.
$$

Assuming that the size effect law is known, $\sigma_{u}=\sigma_{u}(w)$, using (5) in the first of equation (7) yields:

$$
\mathcal{R}(\Delta a)=\frac{1}{E^{\prime}} w \sigma_{u}^{2} \kappa^{2}
$$


This equation is valid for every $w$. Following [11], differentiating (8) with respect to $w$, under the hypothesis that geometrically similar specimens are tested ( $\alpha_{0}$ and $\xi$ are not functions of the width, $w$ ) and remembering that the R-curve does not depend on the size of the specimen $w(\partial \mathcal{R} / \partial w=0)$, the following equation is obtained:

$$
\frac{\partial}{\partial w}\left(w \sigma_{u}^{2} \kappa^{2}\right)=0
$$

Equation (9) can be solved for $w=w(\Delta a)$. Replacing $w$ in (8) yields the R-curve, $\mathcal{R}(\Delta a)$.

The size effect law should be determined by testing geometrically similar specimens. Following Bazant and Planas [11], three different kinds of fitting are generally used: i) the bilogarithmic regression; ii) the linear regression I; iii) the linear regression II. The regression fits normally used, and the corresponding formula for the calculation of the length of the fracture process zone, $l_{f p z}$, and for the fracture toughness at propagation, $\mathcal{R}_{s s}$, are reported in Table 1 where $\kappa_{0}=\left.\kappa\right|_{\alpha=\alpha_{0}}$ and $\kappa_{0}=\partial \kappa /\left.\partial \alpha\right|_{\alpha=\alpha_{0}}$.

[Table 1 about here.]

\subsection{Determination of $\kappa$}

According to Bao et al. [13], the effect of the parameter $\zeta$ is negligible when $\zeta \leq 1 / 2$; therefore, for a sufficiently long specimen the correction factor used in equation (4) will be a function of $\alpha$ and $\rho$ only. Under these circumstances it is possible to express $\kappa$ as:

$$
\kappa=f(\alpha) \chi(\rho)
$$

where $\chi$ is the correction factor for the orthotropy of the material

$$
\chi(\rho)=1+0.1(\rho-1)-0.016(\rho-1)^{2}+0.002(\rho-1)^{3}
$$

$f$ is the configuration correction factor for the dimensionality corresponding to the isotropic case, i.e., when $\rho=1$. The correction factor for the double edge cracked specimen is given in Tada et al. [14]: 


$$
f(\alpha)=\sqrt{\pi \alpha}\left[1+0.122 \cos ^{4}\left(\frac{\alpha \pi}{2}\right)\right] \sqrt{\left(\frac{2}{\alpha \pi}\right) \tan \left(\frac{\alpha \pi}{2}\right)}
$$

For materials with $0 \leq \rho \leq 4$, the error obtained is negligible if $\kappa$ is obtained multiplying the correction factor for isotropic material of equation (12) for the correction for the orthotropy (equation (11)) [13]. Consequently, the solution of equation (10) is applicable in the case of quasi-isotropic laminates (in this case $\chi=1$ and $\kappa=f$ ), or of multidirectional laminates that are not highly orthotropic $(0 \leq \rho \leq 4)$.

If a cross-ply laminate is used, the parameter $\rho$ will not satisfy this inequality, taking values larger than 4 ; therefore equation (10) is not applicable. The importance of determining the expression of $\kappa$ under this circumstances results from the fact that, for a cross-ply laminate, it is possible to obtain easily the R-curve of the ply in the longitudinal direction (i.e. in the fibre direction), knowing the R-curve of the laminate, $\mathcal{R}$.

As observed by Pinho et al. [9], the R-curve of the $0^{\circ}$ plies can be obtained neglecting the fracture toughness of the $90^{\circ}$ plies. The energy balance for a self-similar crack propagation $\mathrm{d} a$ in the cross-ply reads:

$$
\mathcal{R} h \mathrm{~d} a=\mathcal{R}_{0} h_{0} \mathrm{~d} a+\mathcal{R}_{90} h_{90} \mathrm{~d} a
$$

where $\mathcal{R}_{0}$ and $\mathcal{R}_{90}$ are the R-curves for the $0^{\circ}$ and $90^{\circ}$ plies, respectively, and $h, h_{0}$ and $h_{90}$ are the thickness of the laminate, the $0^{\circ}$ and $90^{\circ}$ plies, respectively. Neglecting $\mathcal{R}_{90}\left(\mathcal{R}_{90}<<\mathcal{R}_{0}\right)$, after simplifying, equation (13) can be rearranged as:

$$
\mathcal{R}_{0}=\frac{h}{h_{0}} \mathcal{R}
$$

If a balanced cross-ply is used, $h_{0}=h_{90}=h / 2$; therefore, the R-curve of the ply in the longitudinal direction reads: $\mathcal{R}_{0}=2 \mathcal{R}$. This means that, for a balanced cross ply, the fracture toughness in longitudinal direction, $\mathcal{R}_{0}$, is simply twice the fracture toughness of the laminate, $\mathcal{R}$.

The use of a balanced cross-ply to measure the fracture toughness of the $0^{\circ}$ ply is proposed here. In this case, the influence of $\lambda$ on the calculation of the correction factor, $\kappa$, can be eliminated (because $\kappa=1$ when $s_{11}=s_{22}$ ) and this parameter will only depend on $\alpha, \rho$, and $\xi$. Since equation (10) cannot be used, a new expression for $\kappa$ should be found. Taking advantage of the capabilities of the commercial software Abaqus [15], a parametric model of the specimen was build in Python [16] to calculate the correction factor $\kappa$ for 
different values of $\alpha, \rho$, and $\xi$. One-quarter of the specimen was modeled using 4-node plane stress reduced integration elements (CPS4R) [15] (Figure 2).

The material properties used in the CPS4R elements are the laminate elastic properties, which are either calculated from the ply elastic properties and layup using lamination theory (unidirectional reinforcements), or directly measured in experimental tests (woven fabrics).

Taking into account $\kappa$ will be used in the test method to measure the R-curve of the ply in the longitudinal direction, appropriate boundary conditions must imposed in the finite element model. Therefore, a displacement is applied at the end of the specimens (see Figures 1 and 2). The length of the specimen of Figure 1 corresponds to the free length of the specimen.

[Fig. 2 about here.]

The Virtual Crack Closure Technique [17] is used to calculate the energy release rate. Taking into account the symmetry of the problem, the crack driving force is equal to:

$$
\mathcal{G}_{I}=-Y_{m} u_{n} / l_{e}
$$

where $Y_{m}$ and $u_{l}$ are the load and the displacement in the $x_{2}$ direction of the nodes $m$ and $l$, respectively, and $l_{e}$ is the size of the element (see Figure 2).

The correction function $\kappa$ can be obtained fitting the numerical results using a polynomial function:

$$
\kappa=\sqrt{\tan \frac{\pi \alpha}{2}} \sum_{i} \sum_{j} \sum_{k} K_{i j k} \alpha^{i-1} \rho^{j-1} \xi^{k-1}
$$

where $K_{i j k}$ is the element of the matrix $\boldsymbol{K}$ of indexes $i, j$, and $k$. The values of the components of the matrix $\boldsymbol{K}$ are reported in Table 2.

[Table 2 about here.]

Observing equation (16) it is conclded that the correction factor $\kappa$ depends on $\xi$. Considering also equations (8) and (9) it is clear that the experimental tests should be performed with the same $\xi$ or, in other words, scaling the free length.

Figures 3(a) and 3(b) compare the numerical results and the polynomial fitting surfaces for the two extreme cases of $\xi=0$ (infinitely long specimen) and $\xi=1$, respectively. The average error in the calibration range $(0<\xi \leq 1$, 
$0 \leq \rho \leq 20,0 \leq \alpha \leq 0.9)$ is less than $2 \%$.

[Fig. 3 about here.]

For an infinitely long specimen $(\xi=0)$, the correction factor $\kappa$ reads:

$$
\phi=\left.\kappa\right|_{\xi=0}=\sqrt{\tan \frac{\pi \alpha}{2}} \sum_{i} \sum_{j} \Phi_{i j} \alpha^{i-1} \rho^{j-1}
$$

where $\Phi_{i j}$ is the element of the matrix $\boldsymbol{\Phi}$ of indexes $i$ and $j$. The matrix $\boldsymbol{\Phi}$ reads:

$$
\boldsymbol{\Phi}=\left[\begin{array}{cccc}
1.7482487564 & -0.053754159533 & 0.0040142704949 & -9.8480085881 e-05 \\
-0.76896688866 & -0.0068632911438 & 0.0029984681658 & -0.00010108691939 \\
0.85633404777 & 0.23922363475 & -0.023289123198 & 0.00062358861997 \\
-0.67470597429 & -0.25334178248 & 0.022297779266 & -0.00056784694513 \\
0.18495379886 & 0.084067007027 & -0.0068989066533 & 0.00016783852495
\end{array}\right]
$$

Figure 4 shows the numerical point and the polynomial fitting surface. The average error in the calibration range $(0 \leq \rho \leq 20,0 \leq \alpha \leq 0.9)$ is again less than $2 \%$.

[Fig. 4 about here.]

If the specimen is long enough, equation (17) can be used to approximate the correction factor. The corresponding error is:

$$
\epsilon=\left|\frac{\phi-\kappa_{F E M}}{\kappa_{F E M}}\right|
$$

Figure 5 shows the average error, which is defined in equation (19), as a function of $\xi$. As expected, the error $\epsilon$ increases increasing the shape parameter $\xi$. In the range $0<\xi<0.2$ the error is exactly the same of that for $\xi=0$. In the range $0.2<\xi<0.5$ the error is higher but still less than $5 \%$ and therefore acceptable, equation (17) can still be used to estimate the correction factor $\kappa$. In the range $\xi>0.5$ the error is unacceptably high and equation (16) should be used.

[Fig. 5 about here.] 
Equations (16) and (17) provide an important improvement on the estimation of $\kappa$ when compared with equation (11). Figure 6 shows the correction factor $\kappa$ as a function of $\alpha$ for different values of $\rho$ for an infinitely long specimen. For quasi-isotropic laminates $(\rho=1)$ equations (11) and (17) yield the same results. However, when $\rho$ increases (Figure 6 reports the cases with $\rho=5$ and $\rho=10$ ), the difference between the predictions becomes very high and the use of equations (16)-(17) is recommended.

[Fig. 6 about here.]

Sometimes it is not possible to scale the free length of the specimens or to respect the condition $\xi<0.5$. For example, when testing specimens whose dimensions lie between a large range of sizes (i.e. when a coupon and a structural part are tested). In this case is still possible to obtain the R-curve of the material by an appropriate manipulation of equations (8) and (9). First of all it is convenient to factorize $\kappa$ as follows:

$$
\kappa(\alpha, \rho, \xi)=\phi(\alpha, \rho) \psi(\rho, \xi)
$$

where $\phi$ is the correction factor for an infinitely long specimen (obtained using equation 17 ) and $\psi$ reads:

$$
\psi=1-\sum_{i} \sum_{j} \Psi_{i j} \rho^{i-1} \xi^{j}
$$

$\Psi_{i j}$ is the element of the matrix $\boldsymbol{\Psi}$ of indexes $i$ and $j$ :

$$
\Psi=\left[\begin{array}{cccc}
0.018136304459 & -0.17640537683 & 0.35130642410 & -0.16996415435 \\
-0.0051147015355 & 0.038096285848 & -0.033267185410 & 0.00918499914
\end{array}\right]
$$

Equation (20) is less accurate than equation (16) ; however, because the average error between the fitted function and the numerical points is less than $5 \%$, its use is still acceptable. Figure 7 shows the correction factor $\psi$ as a function of $\rho$ and $\xi$. As expected, when $\xi=0$ (infinetely long specimens), the correction factor $\psi$ is equal to 1 .

[Fig. 7 about here.]

Defining a corrected value of the ultimate stress (or ultimate load) as: 


$$
\hat{\sigma}_{u}=\sigma_{u} \psi(\rho, \xi)
$$

The size effect law, $\hat{\sigma}_{u}=\hat{\sigma}_{u}(w)$, can still be obtained choosing the best regression method of those reported in Table 1. Equations (8) and (9) can be rewritten as:

$$
\begin{gathered}
\mathcal{R}(\Delta a)=\frac{1}{\dot{E}} w \hat{\sigma}_{u}^{2} \phi^{2} \\
\frac{\partial}{\partial w}\left(w \hat{\sigma}_{u}^{2} \phi^{2}\right)=0
\end{gathered}
$$

As previously explained, equation (25) can be solved obtaining $w=w(\Delta a)$ that substituted in equation (24) yields the R-curve, $\mathcal{R}(\Delta a)$.

It should be noted that in the case of multidirectional highly orthotropic laminates (multidirectional laminates with $\rho>4$ ) a solution for the correction factor $\kappa(\alpha, \rho, \zeta)$ is easily obtained. In fact, invoking the orthotropic rescaling technique $^{2}$ [12], equations (16)-(25) are still valid if $\xi$ is replaced by $\zeta$.

\section{$3 \quad$ Experiments}

The proposed methodology is applied to measure the R-curve of the following laminates:

- CP-IM7/8552: [90/0 $]_{8 \mathrm{~s}}$ 16-ply cross-ply laminate with a nominal laminate thickness of $2 \mathrm{~mm}$. The nominal ply thickness is $0.125 \mathrm{~mm}$.

- CP-T800/M21: $[90 / 0]_{8 s}$ 16-ply cross-ply laminate with a nominal laminate thickness of $2 \mathrm{~mm}$. The nominal ply thickness is $0.125 \mathrm{~mm}$.

- QI-T700/AR-2527: $[(0 /-45) /(45 / 0) /(90 / 45) /(-45 / 90)]_{\mathrm{s}} 16$-ply quasi-isotropic laminate with a nominal laminate thickness of $1.3 \mathrm{~mm}$. This lay-up is symmetric by C-PLY ${ }^{\mathrm{TM}}[0 /-45]$ non-crimp fabric (NCF) bi-angle layer, but not-symmetric ply by ply. The nominal ply thickness is $0.08 \mathrm{~mm}$.

2 The orthotropic rescaling technique is based on the rescaling of the $x_{1}$-axis by $\xi=\lambda^{1 / 4} x_{1}$ and it allows to draw a parallel between an orthotropic body $(\lambda \neq 1)$ and a solid with cubic symmetry $(\lambda=1)$. For this reason, even if $\kappa(\alpha, \rho, \xi)$ was formally derived for the case of a cross ply laminate (that is a solid with cubic symmetry being $\lambda=1$ ), if the orthotropic rescaling technique applies, the correction factor for the orthotropic body, $\kappa(\alpha, \rho, \zeta)$, takes the same value of equation (16) substituting $\xi$ by $\zeta$. It should be remembered that $\xi$ and $\zeta$ are both dimensionless parameters and that in the case of a cross ply laminate $\xi=\zeta$. 
- CP-T700/ACE: [0/90] 5 TORAYCA® woven fabric laminate with a nominal thickness of $2 \mathrm{~mm}$ and a nominal fabric thickness of $0.2 \mathrm{~mm}$.

The cross-ply laminates also enable the calculation of the R-curve in the longitudinal direction of the ply. The elastic parameter of the laminates as well as the references to the corresponding previous investigations, are shown in Table 3.

[Table 3 about here.]

The geometry of the specimens is reported in Figure 8. To keep the tolerance under control, in particular concerning the crack length, $a_{0}$, and the width, $2 w$, the specimens were machined in a CNC machine equipped with a $1 \mathrm{~mm}$ drill bit. The use of a $1 \mathrm{~mm}$ drill bit does not lead to sharp crack tips; however this is not problematic because: i) the specimen fails when the crack has already propagated until its critical length; therefore at failure the crack tip is sharp; ii) it has been shown that the fracture toughness measured in a center cracked specimen with a crack machined using a drill bit and in a specimen with a crack manufactured using a thin saw is virtually the same [21]. The free length, $2 l$, was controlled during the experimental tests to ensure that the condition $\xi \leq 0.2$ was always respected. Table 4 shows the size investigated for each laminate and the label corresponding to each size. The test matrix is shown in Table 5.

[Fig. 8 about here.]

[Table 4 about here.]

[Table 5 about here.]

Three specimens were tested for each size at a speed of $1 \mathrm{~mm} / \mathrm{min}$. An Instron 4208 testing machine equipped with a $100 \mathrm{kN}$ load cell was used to perform all the tensile tests. The average and the standard deviation of the remote stresses are shown in Table 6.

[Table 6 about here.]

The pictures of the failed specimens are shown in Figure (9).

[Fig. 9 about here.]

The size effect law (see Table 1) that best fit the data are the bilogarithmic (for CP-IM7/8552 and CP-T800/M21 laminates) and the linear regression I (QI-T700/AR-2527). Figure 10 shows the experimental data and the fitting obtained for all the laminates. The parameters that give the best fitting are:

- $M=1242 \mathrm{MPa} \sqrt{\mathrm{mm}}, N=8.614 \mathrm{~mm}$ for CP-IM7 $/ 8552$; 
- $M=1440 \mathrm{MPa} \sqrt{\mathrm{mm}}, N=3.719 \mathrm{~mm}$ for CP-T800/M21;

- $A=0.656 E-6 \mathrm{MPa}^{-2} \mathrm{~mm}^{-1}, C=0.384 E-5 \mathrm{MPa}^{-2}$ for QI-T700/AR-2527;

- $A=0.672 E-5 \mathrm{MPa}^{-2}, C=3.7 E-007 \mathrm{MPa}^{-2} \mathrm{~mm}^{-1}$ for CP-T700/ACE.

[Fig. 10 about here.]

Knowing the size effect law, the R-curve is calculated solving equations (8) and (9). This is equivalent to obtain the R-curve as envelope of the crack driving force curves. Figure 11 and 12 show the fracture toughness for the ply in the longitudinal direction of the IM7/8552 and T800/M21 laminates, respectively. As explained before these curves are obtained multiplying by two the fracture toughness of the laminate. For the IM7/8552 $0^{\circ} \mathrm{ply}$, the experimental points obtained from the compact tension (CT) specimens are also reported using the FEM based data reduction method proposed in [9].

The steady-state value of the R-curve obtained using the double-edge notched specimens is in good agreement with that obtained using CT specimens. However, some differences are observed on the rising part of the R-curve, and on the length of fracture process zone, $l_{f p z}$. Using double-cantilever beam test specimens, Foote [22] demonstrated that the rising part of the R-curve and the corresponding length of the fracture process zone depend on the specimen size, up to a critical size after which constant R-curves are obtained. This indicates that further studies based on CT test specimens with different sizes are required to clarify the differences observer in the rising part of the R-curve. However, it should be emphasised that the method proposed here provides a robust way to identify the steady-state value of the fracture toughness, corresponding to an improvement over the classical CT test method.

[Fig. 11 about here.]

[Fig. 12 about here.]

Figure 13 shows the R-curve of the QI-T700AR-2527 laminate.

[Fig. 13 about here.]

[Fig. 14 about here.]

The values of the length of the fracture process zone, $l_{f p z}$, and of the steady state value of the fracture toughness of the $0^{\circ} \mathrm{ply}, \mathcal{R}_{0 s s}$, are calculated and shown in Table 7 . For the T700/AR-2527 ply these values are calculated using the analytical model previously developed [21] to predict the fracture toughness of the $0^{\circ}$ ply from that of a multidirectional laminate.

Unfortunately this model cannot be used to determine the fracture toughness of the $0^{\circ}$ ply for the CP-T700/ACE material system. In fact, as shown in 
Figures 9(d) and 15(d), the fracture surface of this materials includes several pulled-out boundles of fibres and a damage region that is not confined to the uncracked ligament of the specimen. Neglecting the energy dissipated by the additional failure mechanism overestimates the fracture toughness of the ply.

[Fig. 15 about here.]

[Table 7 about here.]

To simplify the use of R-curve in numerical and analytical models it is useful to express it analytically. A formula that has shown a good fitting of the R-curve is:

$$
\mathcal{R}=\mathcal{R}_{s s}\left[1-(1-\gamma \Delta a)^{\beta}\right]
$$

where $\gamma$ and $\beta$ are the parameters that best fit the formula to the R-curve. As an example, Figure 16 shows the R-curve for QI-T700/AR-2527 laminate and the corresponding fitting. The parameters that best fit the R-curves of the ply in the longitudinal direction are shown in Table 7.

[Fig. 16 about here.]

A comparison of the R-curves of the $0^{\circ}$ ply in the longitudinal direction for the different materials is shown in Figure 17. It is observed that the T800/M21 material has the highest value of the steady-state fracture toughness, $\mathcal{R}_{0 s s}$, whereas the lowest value is observed for IM7/8552.

[Fig. 17 about here.]

\section{Conclusions}

Using the size effect law measured in composite laminates with two edge cracks it is possible to obtain the crack resistance curve, both for the multiaxial laminate tested and for the $0^{\circ}$ ply. The methodology proposed here circumvents both the need to perform complex post-processing analysis based on Finite Elements and the need to measure the crack length during the test.

The stress intensity factor used in the model can be easily obtained using a polynomial approximation of the results of the application of the Virtual Crack Closure technique in parametric Finite Element models of specimens with two edge cracks loaded in tension. It is concluded that this is the preferred method to calculate the stress intensity factor for general lay-ups and geometries. 
All the three carbon-epoxy material systems investigated here, T800/M21, IM7/8552, and T700/AR-2527 showed a crack resistance curve. The steadystate values of the longitudinal fracture toughness are $205 \mathrm{~kJ} / \mathrm{m}^{2}$ for IM $7 / 8552$, $283 \mathrm{~kJ} / \mathrm{m}^{2}$ for $\mathrm{T} 800 / \mathrm{M} 21$, and $254 \mathrm{~kJ} / \mathrm{m}^{2}$ for the T700/AR-2527 laminates. The respective values of the fracture process zone are $2.63 \mathrm{~mm}, 1.14 \mathrm{~mm}$ and $1.92 \mathrm{~mm}$. It should be noted that the previous attempts to measure the Rcurve of T800/M21 using compact tension test specimens were not successful due to specimen buckling [10]; however, using the method proposed here it was possible to obtain the R-curve of T800/M21.

The methodology proposed here provides a robust way to measure the steadystate value of the R-curve for fibre-reinforced composites, if compared with the CT specimen, for which the determination of the steady-state value may be ineffective.

The information generated in this paper will be used in the definition of the constitutive relations of the analysis models that aim to predict the mechanisms of crack initiation and propagation of composite structures.

\section{Acknowledgements}

This work was funded by AIRBUS under the project 2genComp - Second generation composites. The authors gratefully acknowledge the support provided by AIRBUS, and Dr. Peter Linde for the useful discussions.

The first and the second authors would like to acknowledge the support of the Portuguese Foundation for Science and Technology under the grants FCTDFRH-SFRH-BPD-78104-2011 and FCT-DFRH-SFRH-BD-88593-2012, respectively.

\section{References}

[1] Abisset E, Daghia F, Ladevèze P. On the validation of a damage mesomodel for laminated composites by means of open-hole tensile tests on quasi-isotropic laminates. Compos Part A Appl Sci Manuf, 42(10):1515 - 1524, 2011.

[2] Schuecker C, Pettermann HE. A continuum damage model for fiber reinforced laminates based on ply failure mechanisms. Compos Struct, 76(1-2):162 - 173, 2006.

[3] Camanho PP, Bessa MA, Catalanotti G, Vogler M, Rolfes R. Modeling the inelastic deformation and fracture of polymer composites - part II: smeared crack model. Mech Mater. submitted. 
[4] Dávila CG, Rose CA, Camanho PP. A procedure for superposing linear cohesive laws to represent multiple damage mechanisms in the fracture of composites. Int J Fracture, 158(2):211-223, 2009.

[5] Camanho PP, Erçin GH, Catalanotti G, Mahdi S, Linde P. A finite fracture mechanics model for the prediction of the open-hole strength of composite laminates. Compos Part A Appl Sci Manuf, 43(8):1219 - 1225, 2012.

[6] Erçin GH, Camanho PP, Xavier J, Catalanotti G, Mahdi S, Linde P. Size effects on the tensile and compressive failure of notched composite laminates. Compos Struct, 96(0):736 - 744, 2013.

[7] Martin E, Leguillon D, Carrère N. A coupled strength and toughness criterion for the prediction of the open hole tensile strength of a composite plate. Int J Solids Struct, 49(26):3915 - 3922, 2012.

[8] Catalanotti G, Camanho PP. A semi-analytical method to predict net-tension failure of mechanically fastened joints in composite laminates. Compos Sci Technol, 76(0):69 - 76, 2013.

[9] Pinho ST, Robinson P, Iannucci L. Fracture toughness of the tensile and compressive fibre failure modes in laminated composites. Compos Sci Technol, 66:2069-2079, 2006.

[10] Erçin GH. Stress gradient effects in laminated composites. PhD thesis, University of Porto, 2013.

[11] Bažant ZP, Planas J. Fracture and Size Effect in Concrete and Other Quasibrittle Materials. CRC Press LLC, 1997.

[12] Suo Z, Bao G, Fan B, Wang TC. Orthotropy rescaling and implications for fracture in composites. Int J Solids Struct, 28:235-248, 1990.

[13] Bao G, Ho S, Suo Z, Fan B. The role of material orthotropy in fracture specimens for composites. Int J Solids Struct, 29(9):1105-1116, 1992.

[14] Tada H, Paris PC, Irwin GR. Stress analysis of cracks handbook. Del Research Corporation, 1973.

[15] Dassault Systèmes. Abaqus Version 6.8-3 Documentation, 2008.

[16] Lutz M. Learning Python. O’Reilly Media, Inc., 3rd edition, 2008.

[17] Krueger R. The virtual crack closure technique: History, approach and applications. Technical Report NASA/CR-2002-211628 ICASE Report No. 2002-10, ICASE, Hampton, Virginia, April 2002.

[18] Camanho PP, Maimí P, Dávila CG. Prediction of size effects in notched laminates using continuum damage mechanics. Compos Sci Technol, 67(13):2715-2727, 2007.

[19] Arteiro A, Catalanotti G, Xavier J, Camanho PP. Notched response of noncrimp fabric thin-ply laminates. Compos Sci Technol, 79(0):97 - 114, 2013. 
[20] Catalanotti G, Pinto R, Camanho PP. Technical report D-AG-20120414-T-C4PB. University of Porto, 2013.

[21] Camanho PP, Catalanotti G. On the relation between the mode I fracture toughness of a composite laminate and that of a $0^{\circ}$ ply: Analytical model and experimental validation. Eng Fract Mech, 78(13):2535-2547, 2011.

[22] Foote RML, Mai Y-W, Cotterell B. Crack growth resistance curves in strainsoftening materials. J Mech Phys Solids, 34:593-607, 1986. 


\section{List of Figures}

1 Double edge cracked specimen (DEC).

$3 \quad$ Numerical results and polynomial fitting for $\kappa$ (equation (16))

$4 \quad$ Numerical results and polynomial fitting for $\phi$ (equation (17))

22

5 Average error as a function of $\xi$.

$6 \quad$ Correction factor $\kappa$ vs. $\alpha$ for different values of $\rho$.

$7 \quad \psi$ as a function of $\rho$ and $\xi$.

8 Technical draw of the specimen. 26

$9 \quad$ Specimen after testing. 27

10 Size effect laws: experiments and fitting for the investigated material.

11 R-curve of the $0^{\circ}$ ply for IM7/8552 (in black) obtained as envelope of the driving force curves (in blue) and comparison with experimental results obtained using CT specimens (every marker a different specimen).

12 R-curve of the $0^{\circ}$ ply for T800/M21 (in black) and the corresponding driving force curves (in blue).

13 R-curve of the QI-T700/AR-2527 quasi-isotropic laminate (in black) and the corresponding driving force curves (in blue).

14 R-curve of the CP-T700/ACE quasi-isotropic laminate (in black) and the corresponding driving force curves (in blue).

15 Typical fracture surface observed in all the laminate tested (specimen type B).

16 R-curve and fitting of the T700/AR-2527 quasi-isotropic laminate.

17 R-curves of the ply in the longitudinal direction for the materials investigated. 


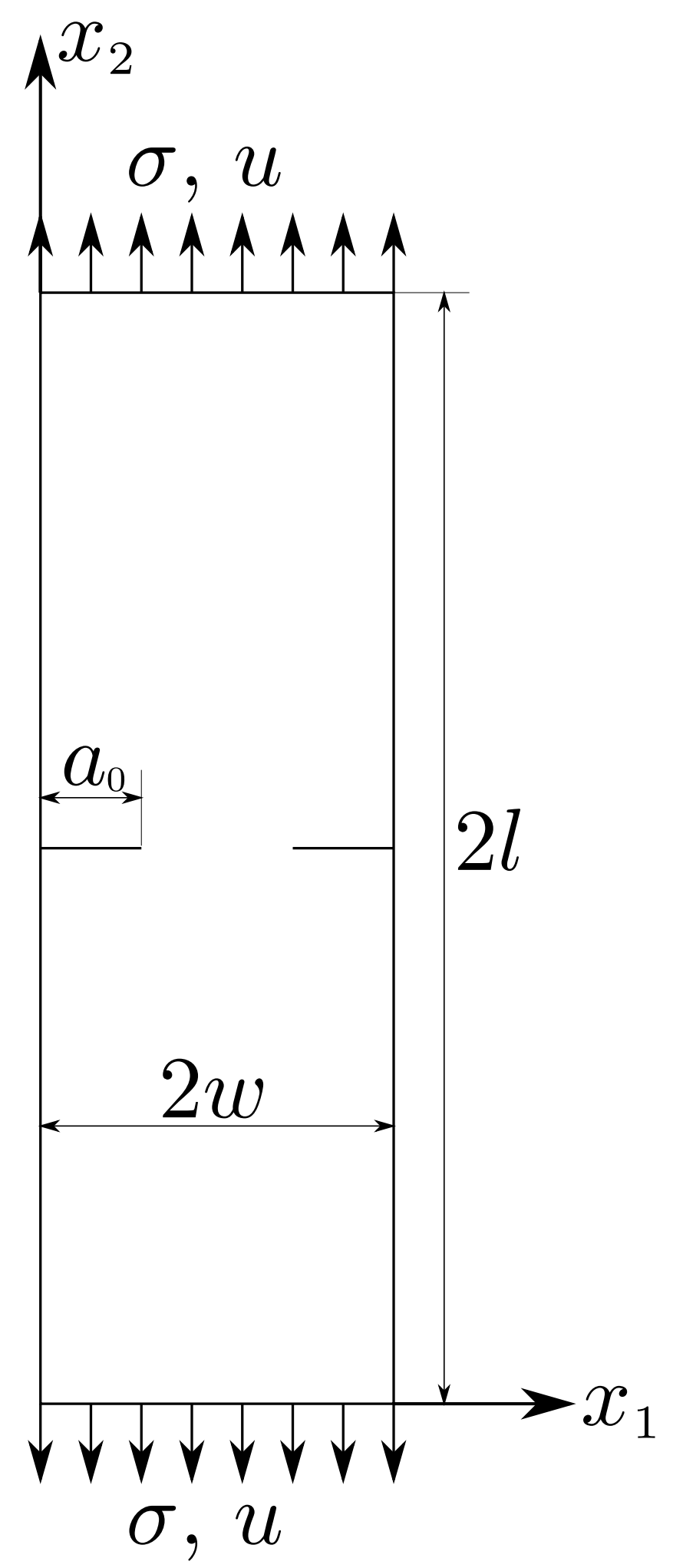

Fig. 1. Double edge cracked specimen (DEC). 


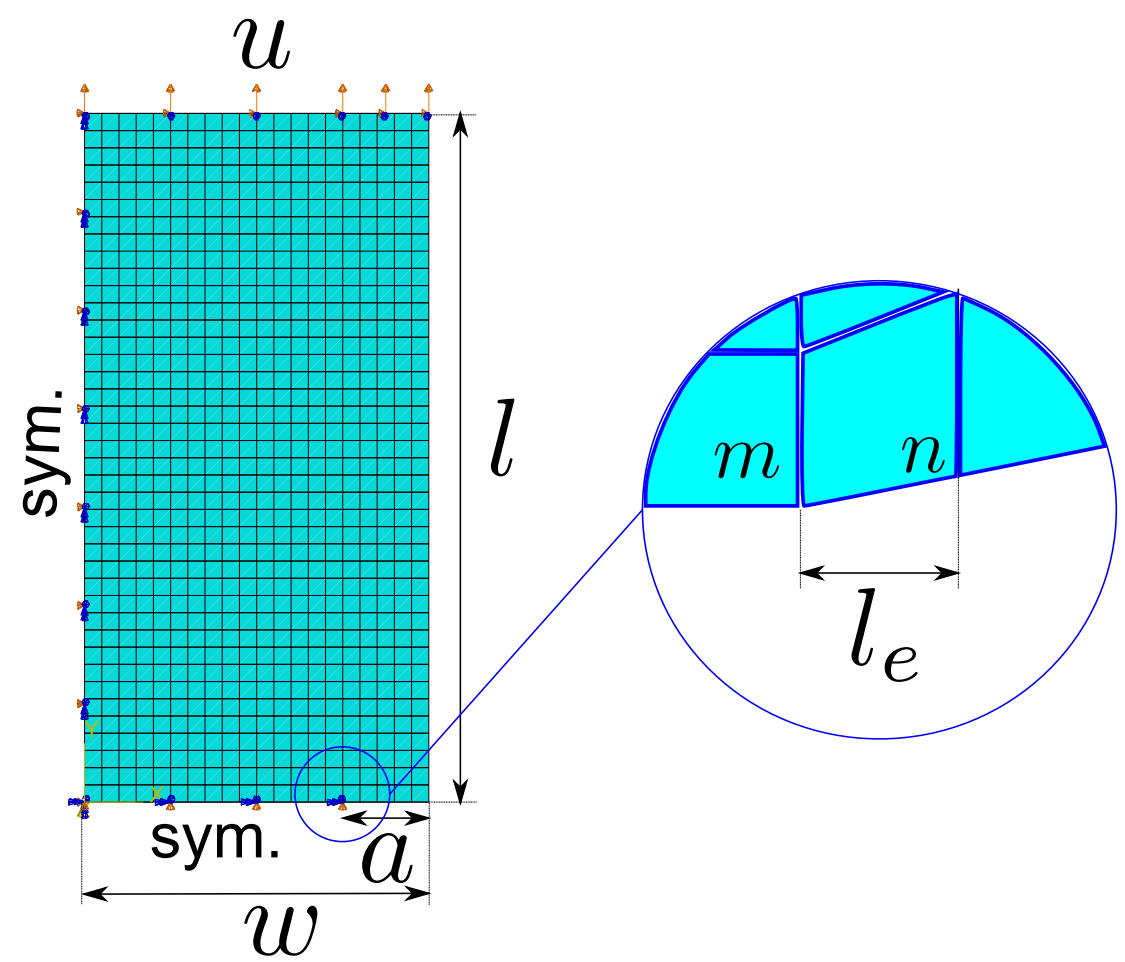

Fig. 2. Finite element model using for the calibration of $\kappa$. 


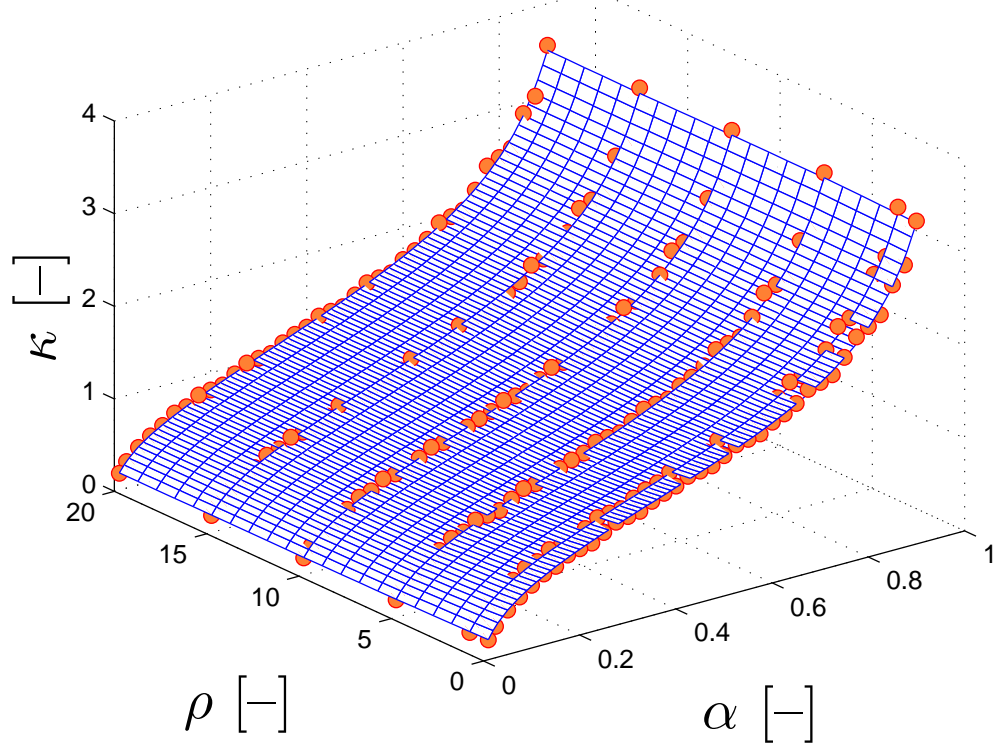

(a) $\xi=0$

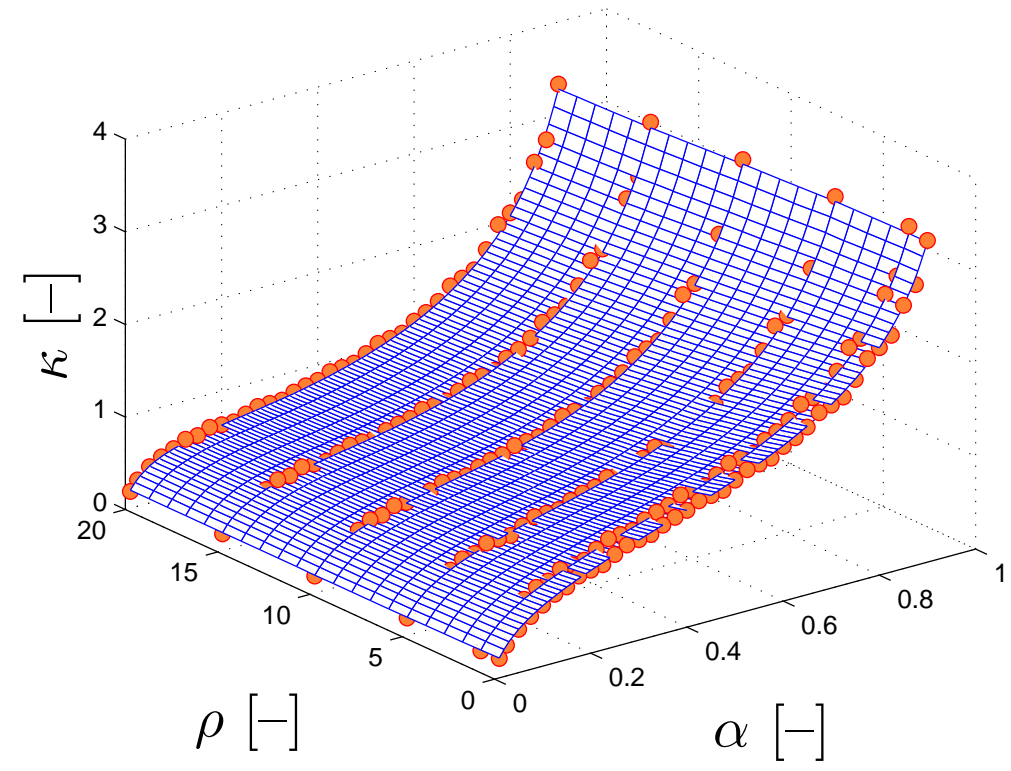

(b) $\xi=1$

Fig. 3. Numerical results and polynomial fitting for $\kappa$ (equation (16)). 


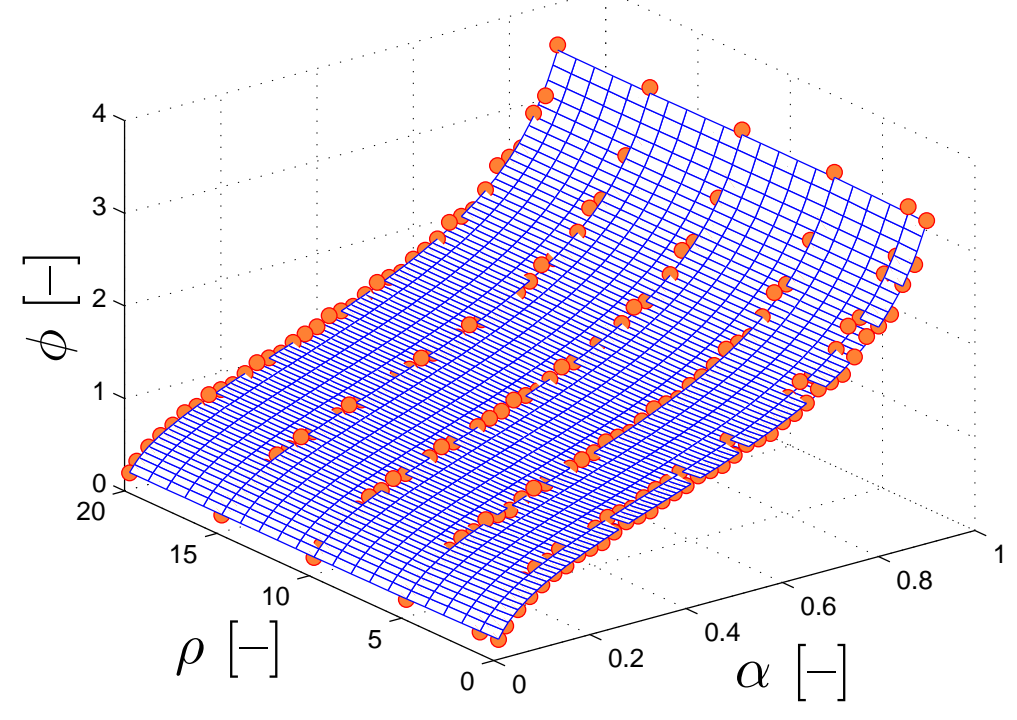

Fig. 4. Numerical results and polynomial fitting for $\phi$ (equation (17)). 


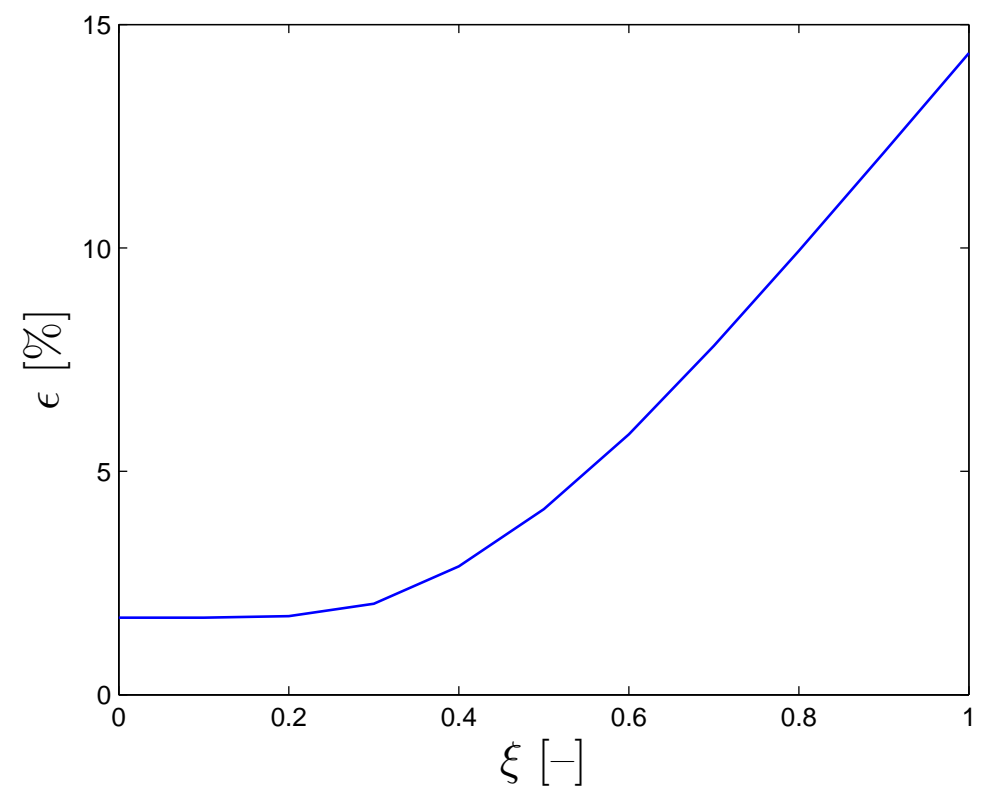

Fig. 5. Average error as a function of $\xi$. 


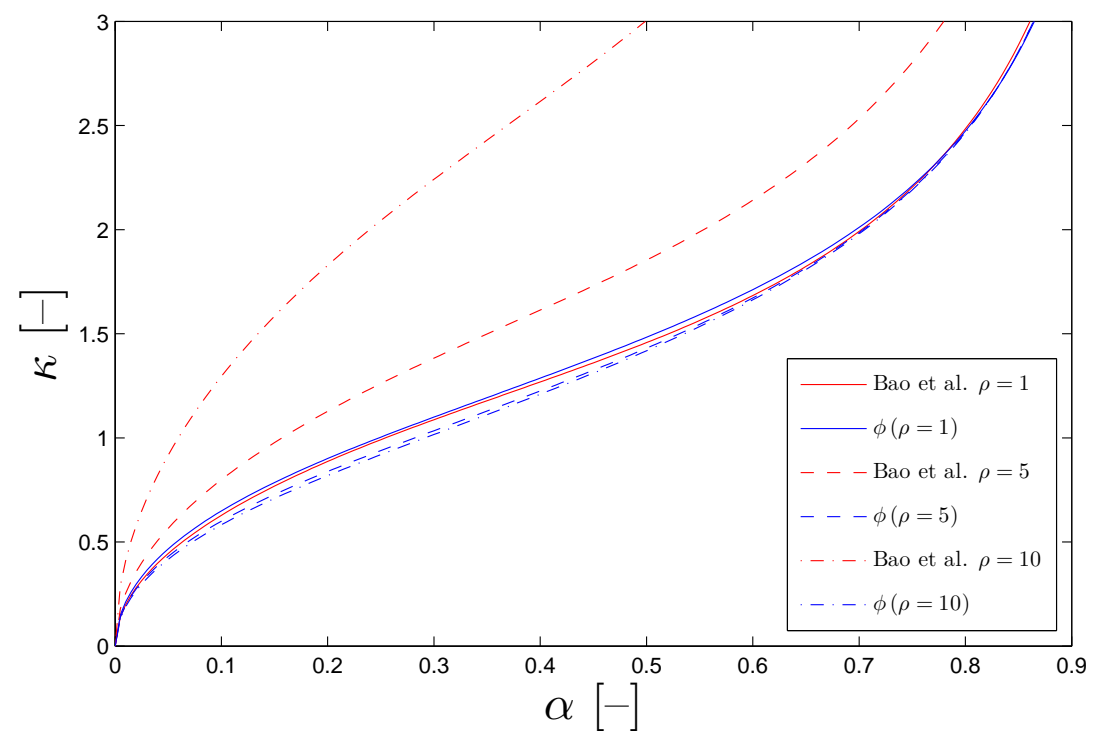

Fig. 6. Correction factor $\kappa$ vs. $\alpha$ for different values of $\rho$. 


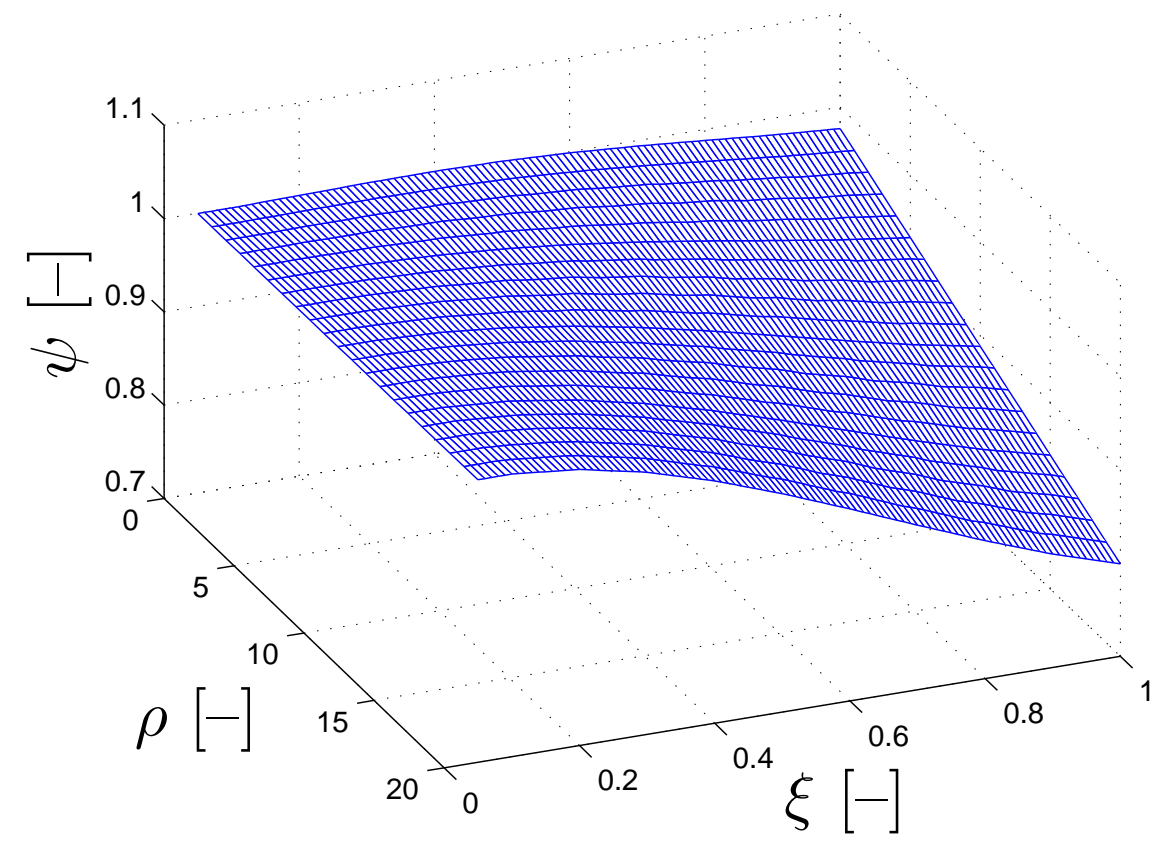

Fig. 7. $\psi$ as a function of $\rho$ and $\xi$. 


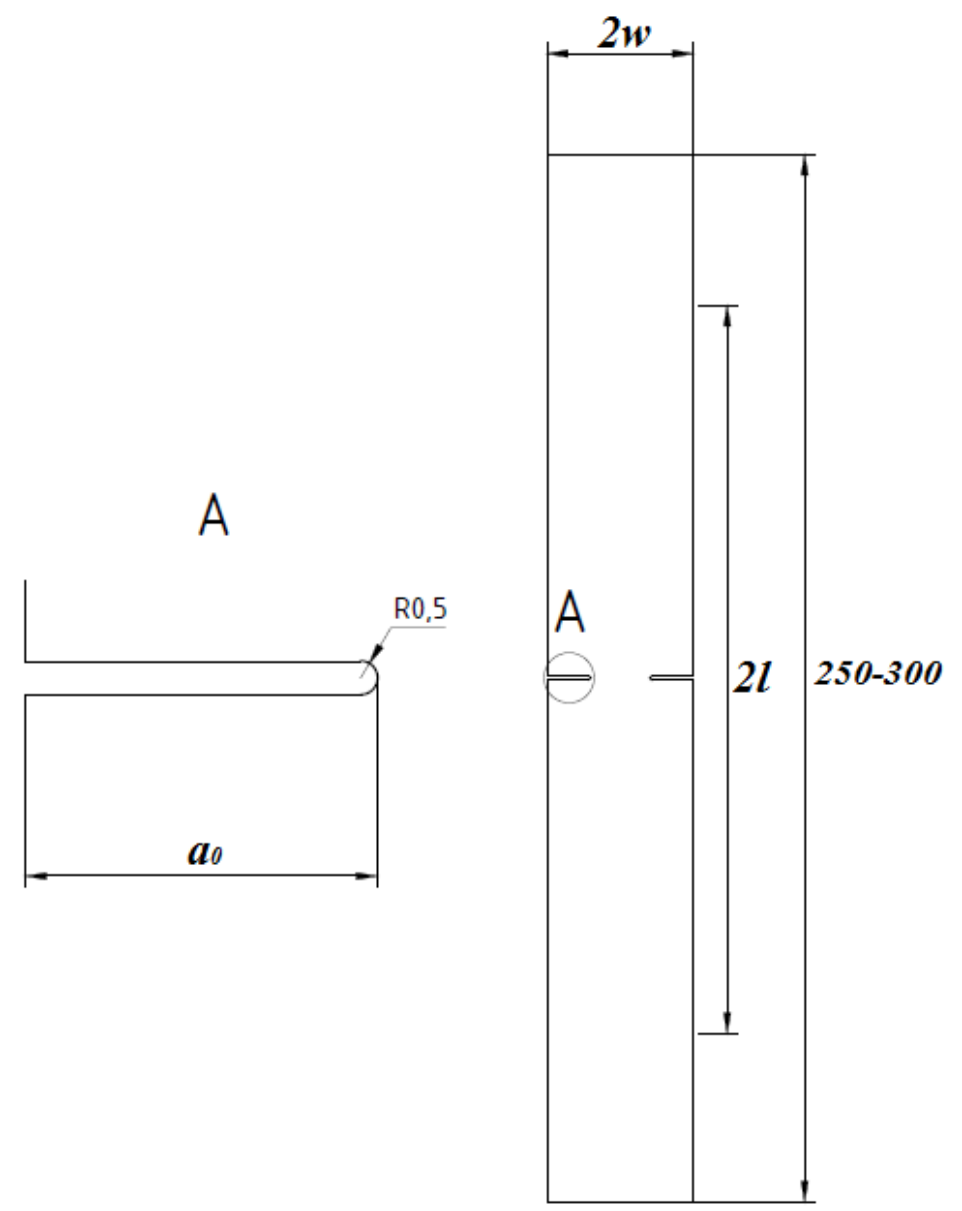

Fig. 8. Technical draw of the specimen. 


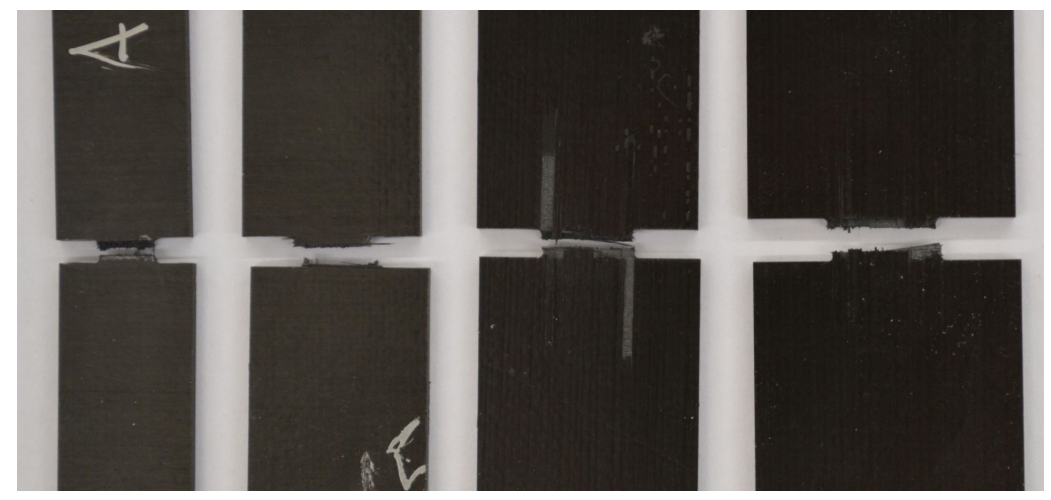

(a) CP-IM7/8552

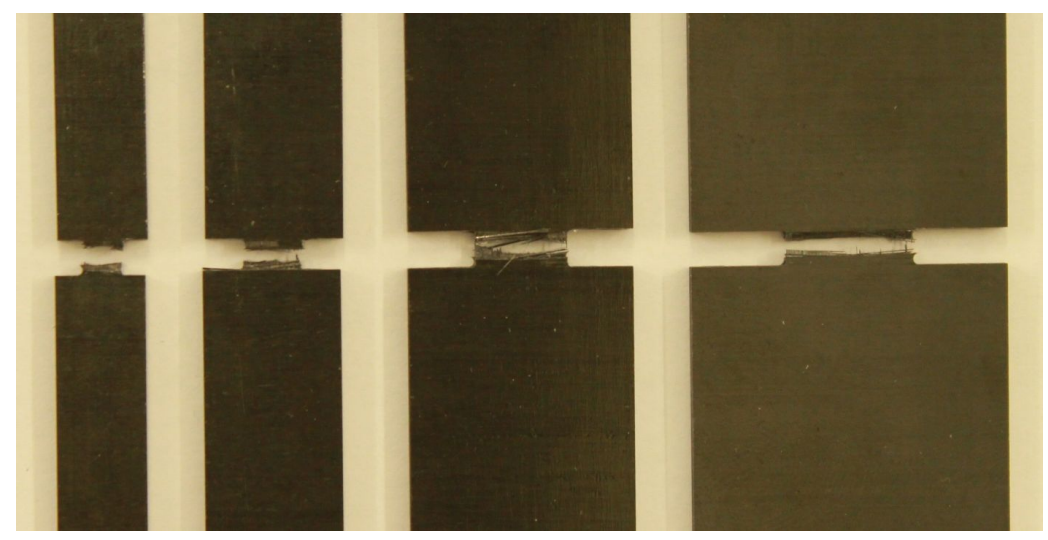

(b) CP-T800/M21

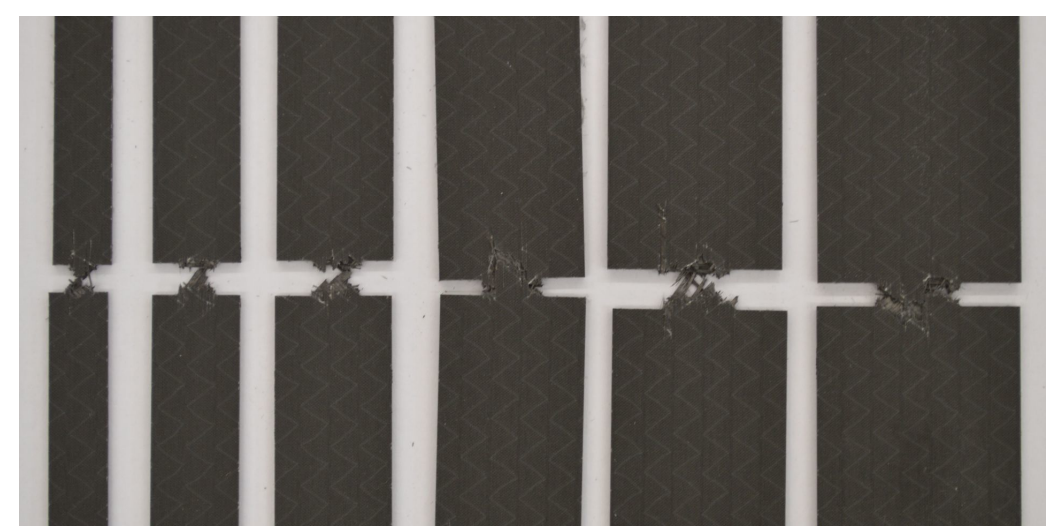

(c) QI-T700/AR-2527

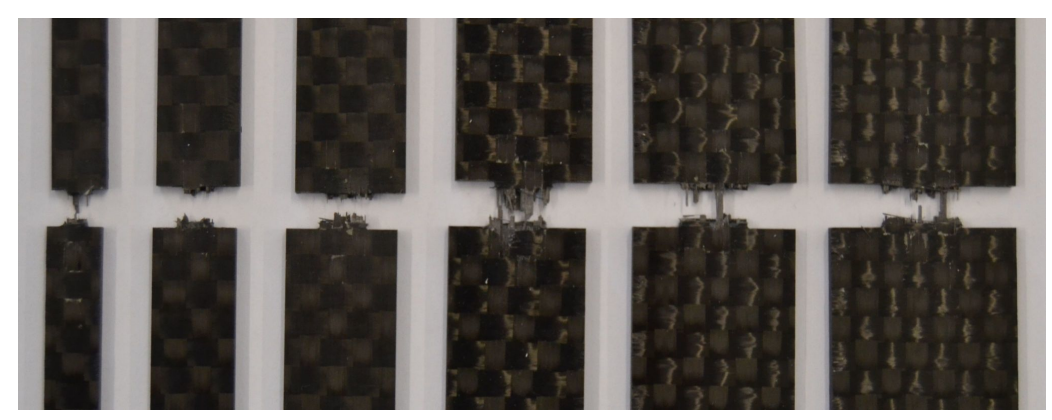

(d) CP-T700/ACE

Fig. 9. Specimen after testing. 


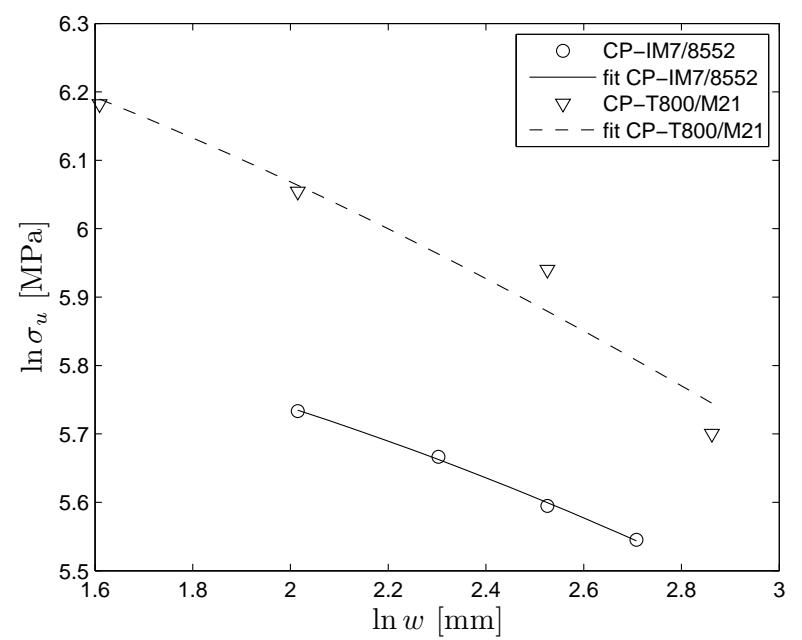

(a) bilogarithmic

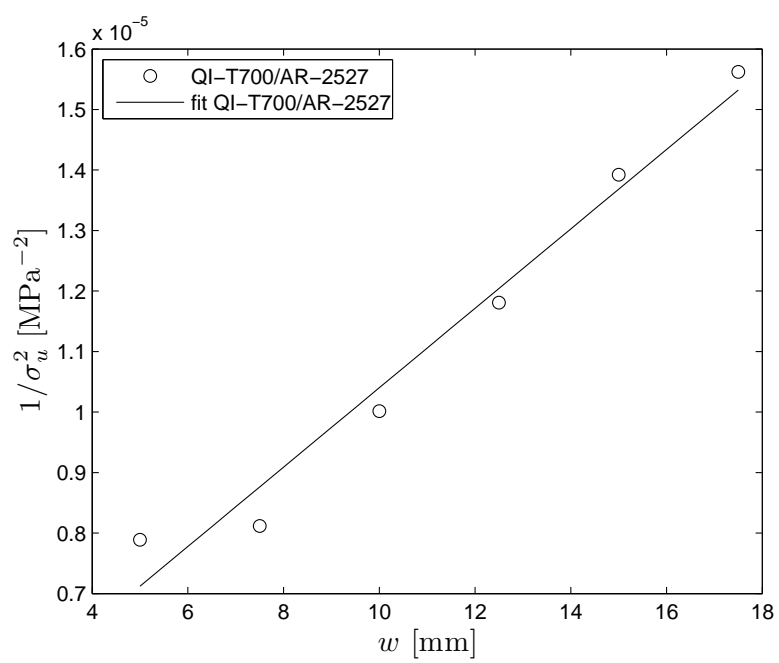

(b) linear regression I

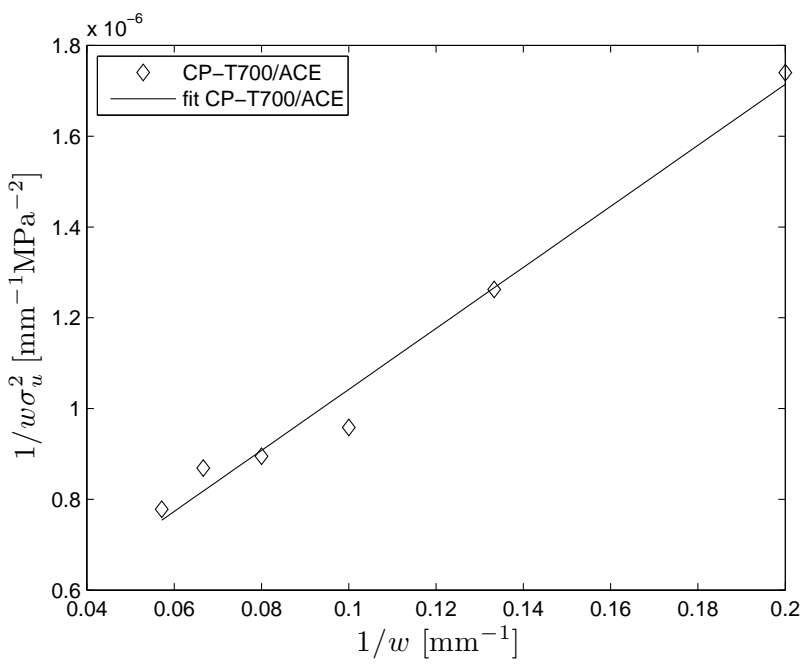

(c) linear regression II

Fig. 10. Size effect laws: experiments and fitting for the investigated material. 


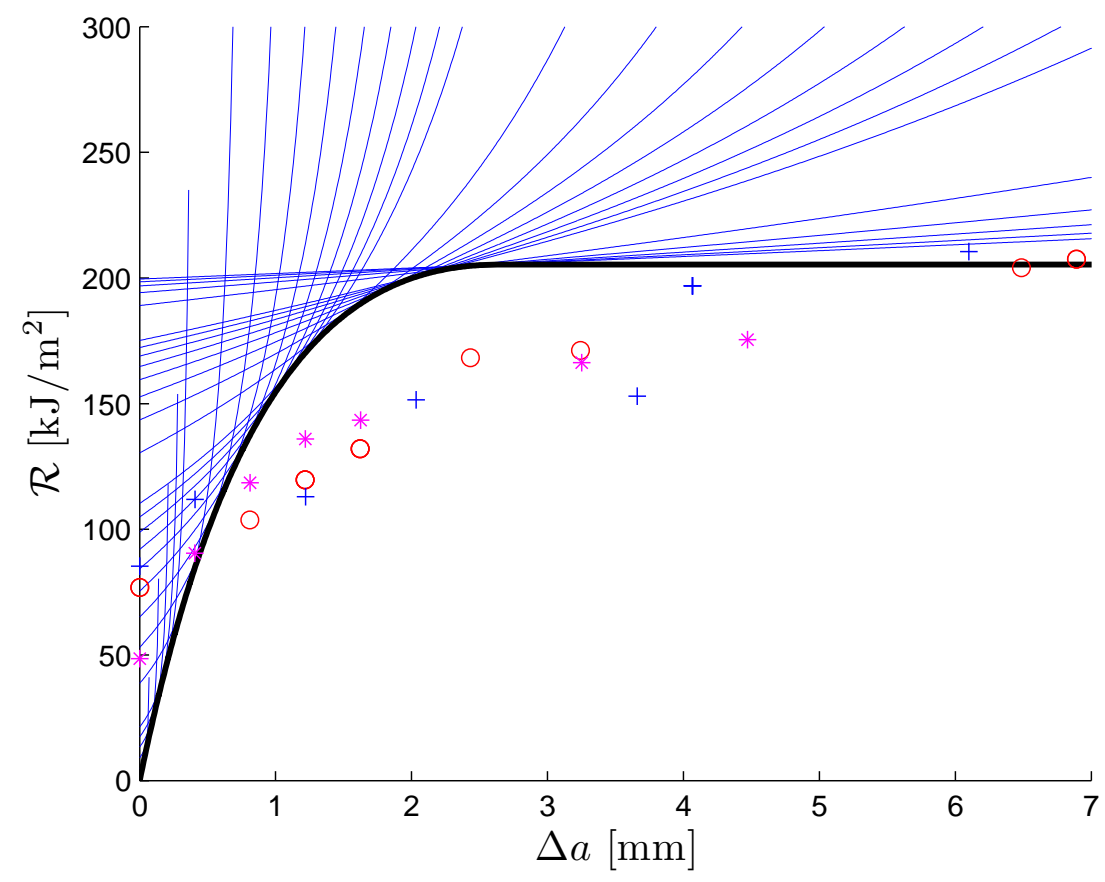

Fig. 11. R-curve of the $0^{\circ}$ ply for IM7/8552 (in black) obtained as envelope of the driving force curves (in blue) and comparison with experimental results obtained using CT specimens (every marker a different specimen). 


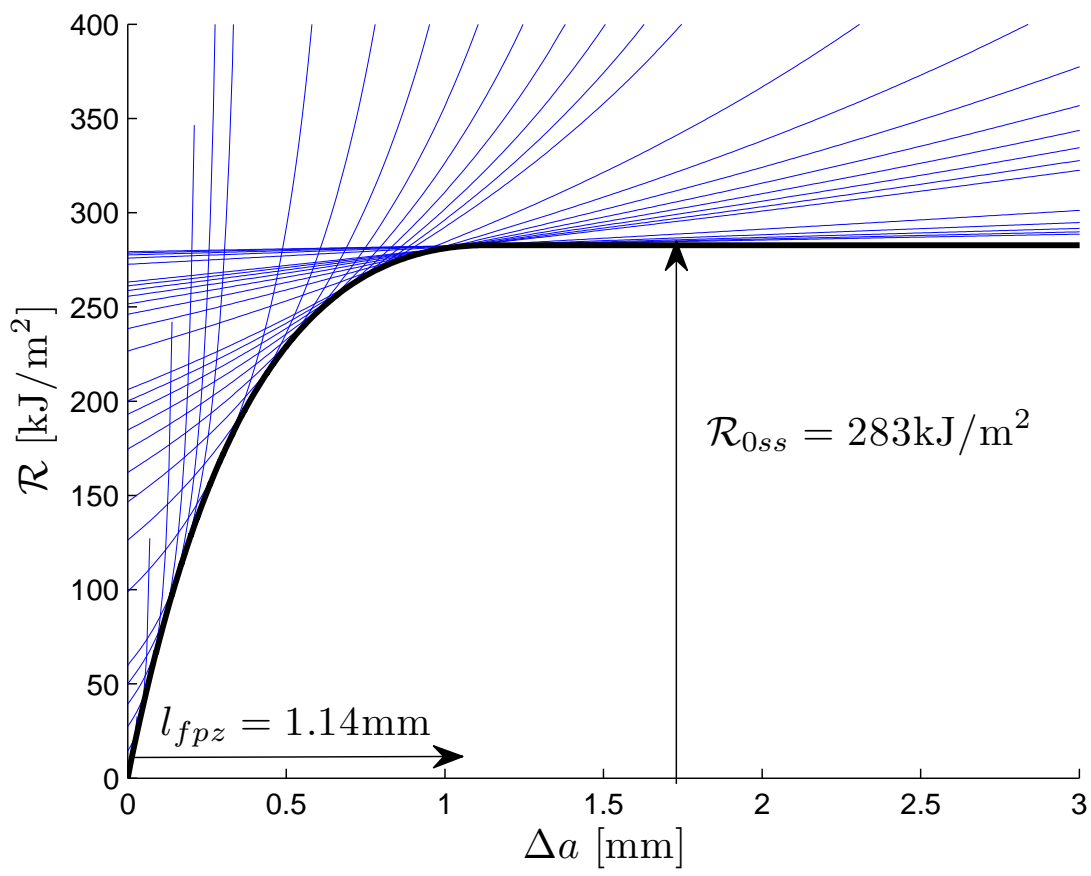

Fig. 12. R-curve of the $0^{\circ}$ ply for T800/M21 (in black) and the corresponding driving force curves (in blue). 


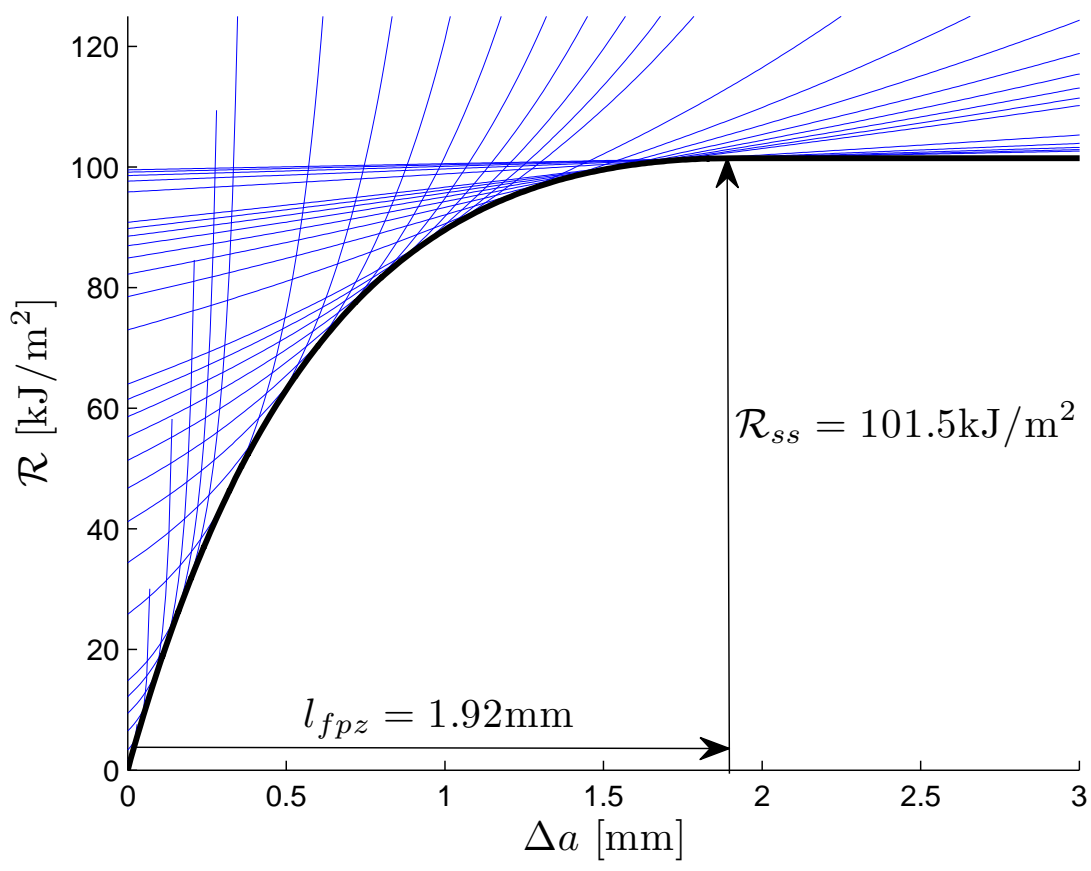

Fig. 13. R-curve of the QI-T700/AR-2527 quasi-isotropic laminate (in black) and the corresponding driving force curves (in blue). 


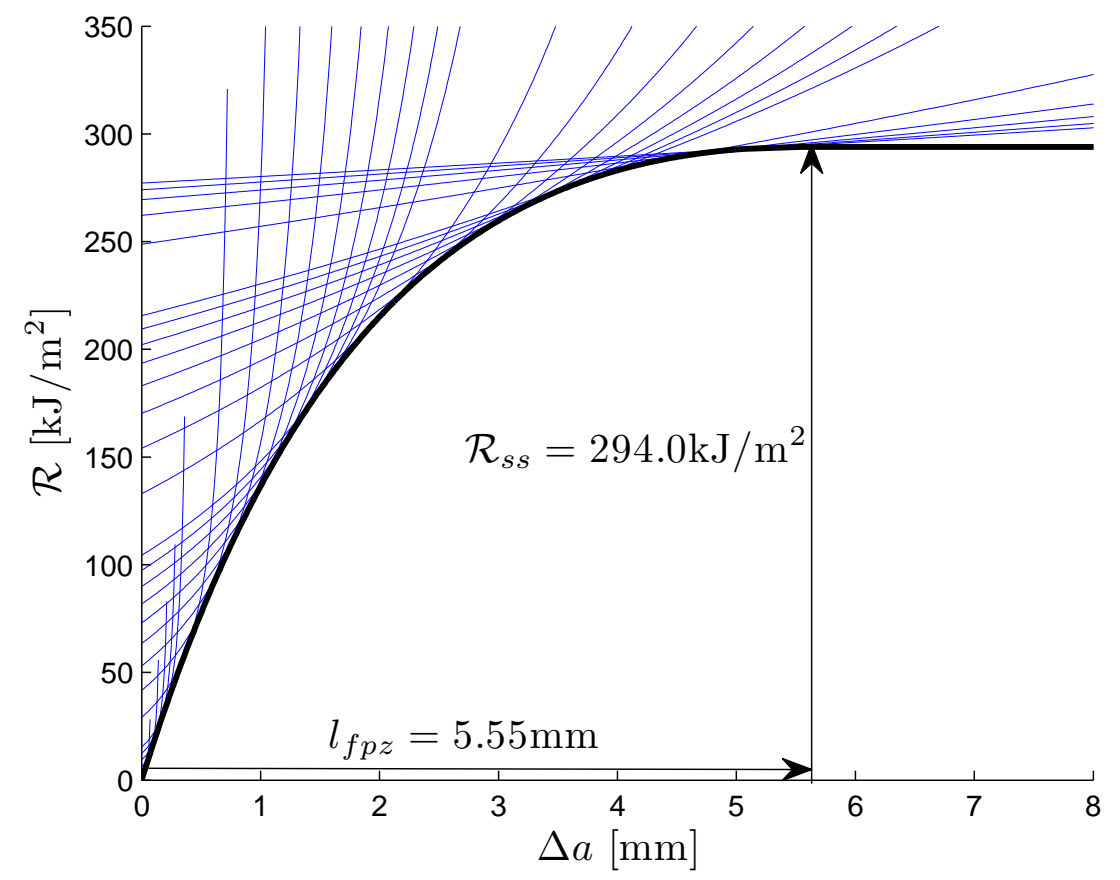

Fig. 14. R-curve of the CP-T700/ACE quasi-isotropic laminate (in black) and the corresponding driving force curves (in blue). 


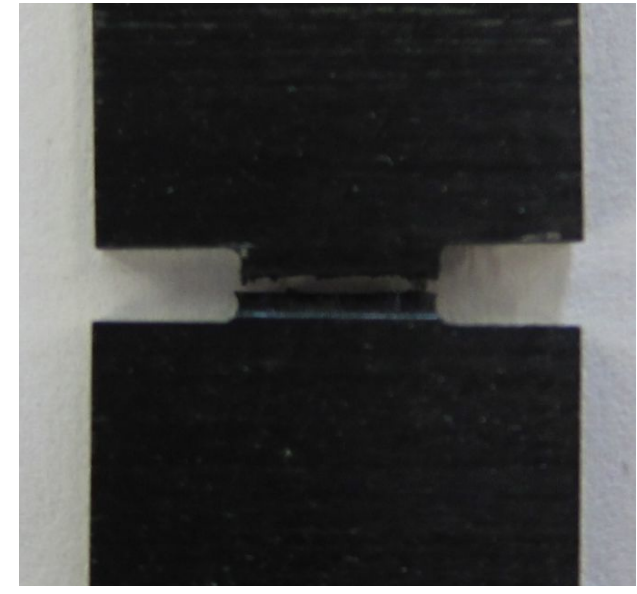

(a) CP-IM7/8552

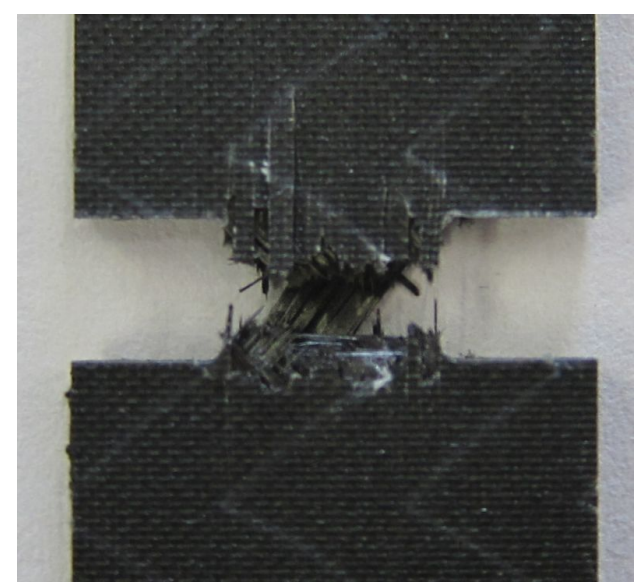

(c) QI-T700/AR-2527

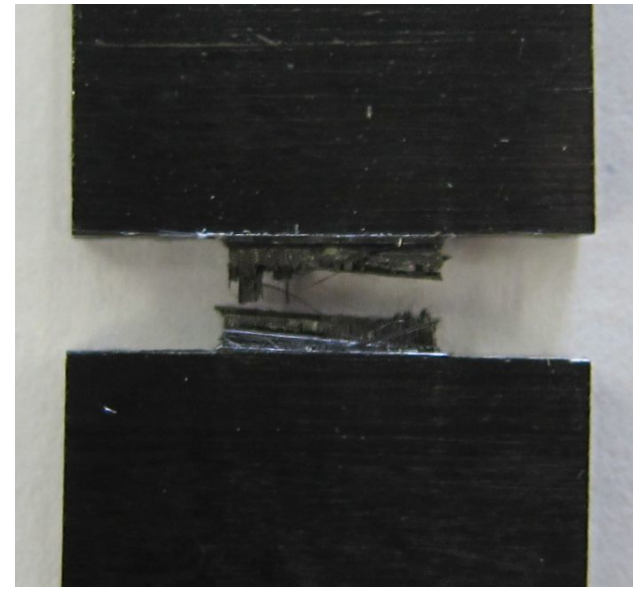

(b) CP-T800/M21

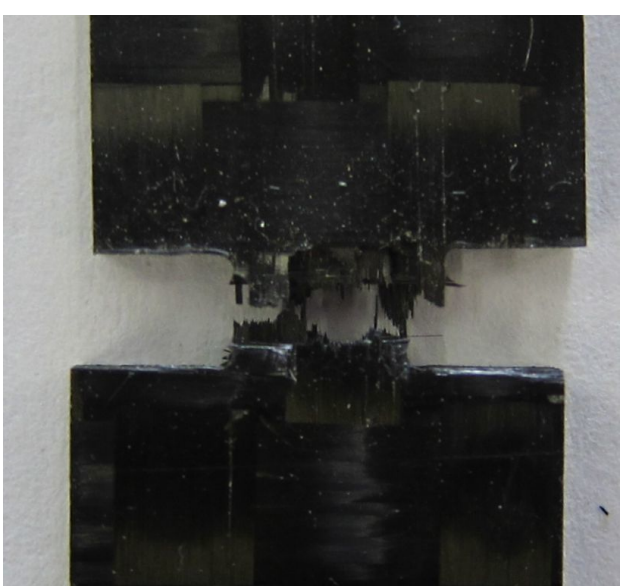

(d) CP-T700/ACE

Fig. 15. Typical fracture surface observed in all the laminate tested (specimen type B). 


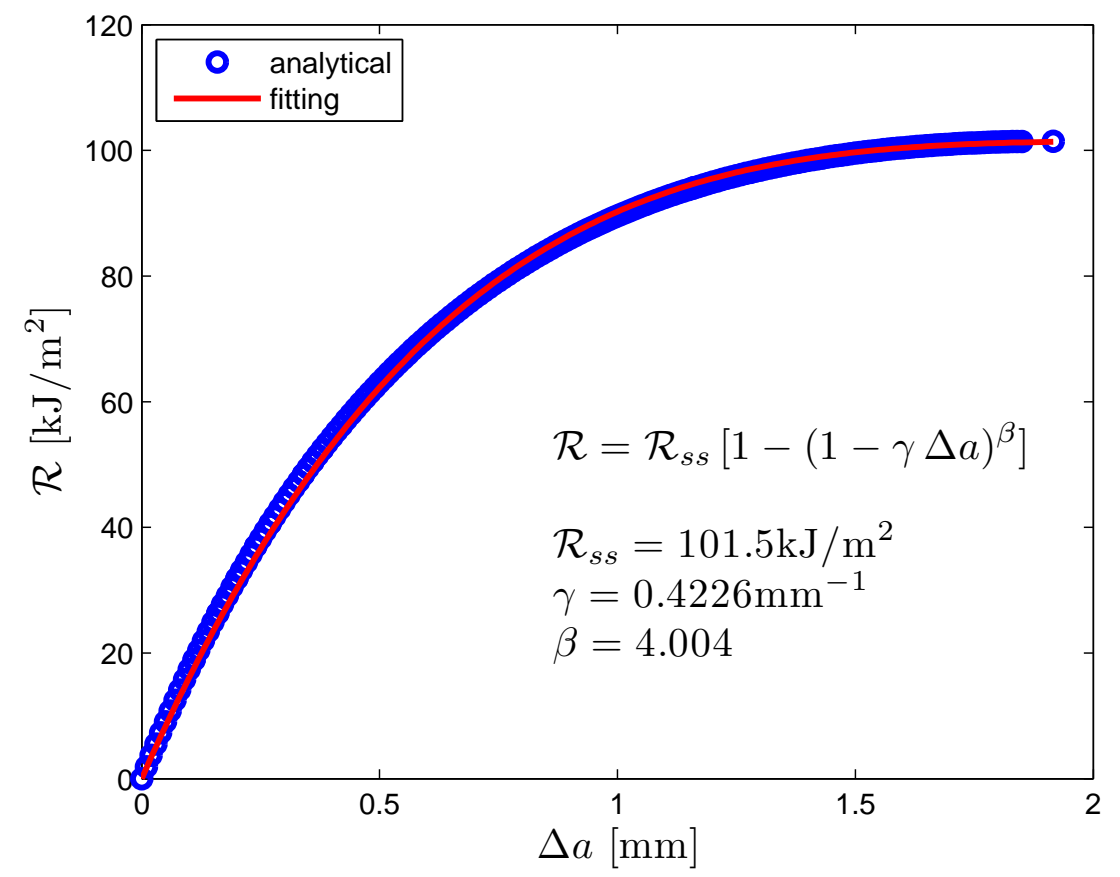

Fig. 16. R-curve and fitting of the T700/AR-2527 quasi-isotropic laminate. 


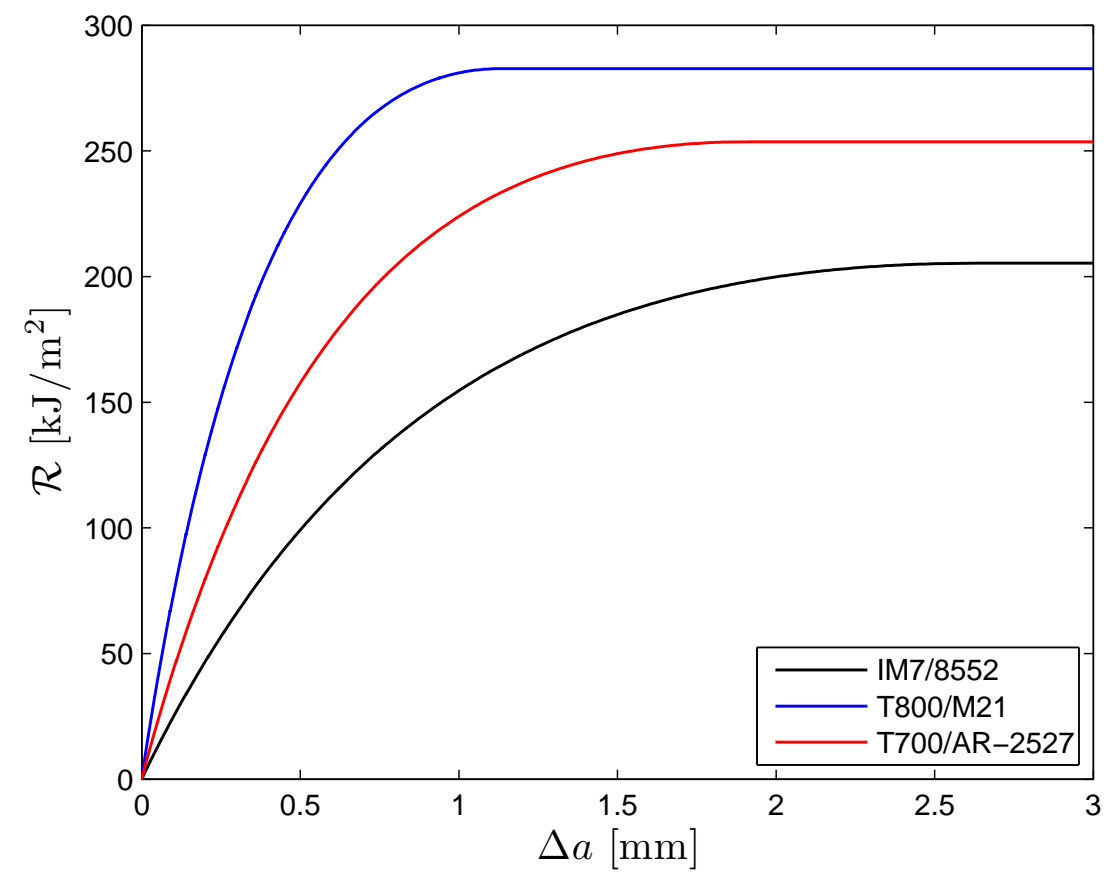

Fig. 17. R-curves of the ply in the longitudinal direction for the materials investigated. 
$431 \quad 1 \quad$ Size effect law fits [11]

432 2 Elements of the $K$ matrix.

38

$433 \quad 3$ Laminates investigated.

$434 \quad 4$ Specimen geometry.

${ }_{435} \quad 5 \quad$ Test matrix.

436 6 Average and standard deviation of the ultimate remote stress,

${ }_{437} \quad \sigma_{u}$ (in $\left.\mathrm{MPa}\right)$.

${ }_{438} 7$ Parameter of the R-curve in the longitudinal direction of the $439 \quad$ ply 


\begin{tabular}{lcccc}
\hline \hline Regressions fit & Formula & Fitting parameters & $\mathcal{R}_{s s}$ & $l_{f p z}$ \\
\hline Bilogarithmic & $\ln \sigma_{u}=\ln \frac{M}{\sqrt{N+w}}$ & $M, N$ & $\frac{\kappa_{0}^{2}}{\dot{E}} M^{2}$ & $\frac{\kappa_{0}}{2 \kappa_{0}} N$ \\
Linear regression I & $\frac{1}{\sigma_{u}^{2}}=A w+C$ & $A, C$ & $\frac{\kappa_{0}^{2}}{\dot{E}} \frac{1}{A}$ & $\frac{\kappa_{0}}{2 \kappa_{0}} \frac{C}{A}$ \\
Linear regression II & $\frac{1}{w \sigma_{u}^{2}}=A \frac{1}{w}+C$ & $A, C$ & $\frac{\kappa_{0}^{2}}{\dot{E}} \frac{1}{\dot{C}}$ & $\frac{\kappa_{0}}{2 \kappa_{0}} \frac{\dot{A}}{\dot{C}}$ \\
\hline \hline
\end{tabular}

Table 1

Size effect law fits [11]. 


\begin{tabular}{|c|c|c|c|c|c|c|c|}
\hline$i$ & $j$ & $k$ & $K(i, j, k)$ & $i$ & $j$ & $k$ & $K(i, j, k)$ \\
\hline 1 & 1 & 1 & 1.74874169287311 & 3 & 3 & 1 & -0.0163543233856253 \\
\hline 1 & 1 & 2 & 0.00714960132308337 & 3 & 3 & 2 & -0.110059901240345 \\
\hline 1 & 1 & 3 & -0.0356324675667488 & 3 & 3 & 3 & 0.203663008343557 \\
\hline 1 & 2 & 1 & -0.0526303311437509 & 3 & 4 & 1 & 0.000263571025795895 \\
\hline 1 & 2 & 2 & -0.0133183413168479 & 3 & 4 & 2 & 0.00433112725257584 \\
\hline 1 & 2 & 3 & 0.0234077533074353 & 3 & 4 & 3 & -0.00658541595211619 \\
\hline 1 & 3 & 1 & 0.00393368572531936 & 4 & 1 & 1 & -0.592470330296433 \\
\hline 1 & 3 & 2 & 0.000726535951382543 & 4 & 1 & 2 & -0.984700920323280 \\
\hline 1 & 3 & 3 & -0.000867546012453078 & 4 & 1 & 3 & 1.78897127917155 \\
\hline 1 & 4 & 1 & $-9.78955615222354 \mathrm{e}-05$ & 4 & 2 & 1 & -0.302437427062842 \\
\hline 1 & 4 & 2 & $-3.48057443564002 \mathrm{e}-06$ & 4 & 2 & 2 & -0.111538580444948 \\
\hline 1 & 4 & 3 & $2.32697528948074 \mathrm{e}-06$ & 4 & 2 & 3 & 1.46770359644942 \\
\hline 2 & 1 & 1 & -0.767208701652775 & 4 & 3 & 1 & 0.00446242346729918 \\
\hline 2 & 1 & 2 & 0.0278810474891446 & 4 & 3 & 2 & 0.231728483007845 \\
\hline 2 & 1 & 3 & -0.157514192137989 & 4 & 3 & 3 & -0.366847699226865 \\
\hline 2 & 2 & 1 & -0.0338305033576344 & 4 & 4 & 1 & 0.000182071222365654 \\
\hline 2 & 2 & 2 & 0.207433832357023 & 4 & 4 & 2 & -0.00822678007628292 \\
\hline 2 & 2 & 3 & -0.177099439797605 & 4 & 4 & 3 & 0.0111920357855815 \\
\hline 2 & 3 & 1 & 0.00417757542138585 & 5 & 1 & 1 & 0.140766754998207 \\
\hline 2 & 3 & 2 & -0.000834205920090498 & 5 & 1 & 2 & 0.572777961274980 \\
\hline 2 & 3 & 3 & -0.0205786990826619 & 5 & 1 & 3 & -1.12893905581246 \\
\hline 2 & 4 & 1 & $-9.62916671898641 \mathrm{e}-05$ & 5 & 2 & 1 & 0.101727935542504 \\
\hline 2 & 4 & 2 & -0.000322325843661191 & 5 & 2 & 2 & 0.108348678423743 \\
\hline 2 & 4 & 3 & 0.000945832449681189 & 5 & 2 & 3 & -0.779004510684639 \\
\hline 3 & 1 & 1 & 0.815416824739527 & 5 & 3 & 1 & 0.00293052383668594 \\
\hline 3 & 1 & 2 & 0.385474036008317 & 5 & 3 & 2 & -0.122154495971872 \\
\hline 3 & 1 & 3 & -0.484668819900970 & 5 & 3 & 3 & 0.186022036976596 \\
\hline 3 & 2 & 1 & 0.297280482414042 & 5 & 4 & 1 & -0.000230184088065499 \\
\hline 3 & 2 & 2 & -0.196826534461867 & 5 & 4 & 2 & 0.00425506303131702 \\
\hline 3 & 2 & 3 & -0.530314776856868 & 5 & 4 & 3 & -0.00561050809815955 \\
\hline
\end{tabular}

Elements of the $K$ matrix. 


\begin{tabular}{lcccc}
\hline \hline \multirow{2}{*}{ Laminates } & \multicolumn{3}{c}{ Laminate's elastic parameters } & Ref. \\
& $E_{x}[\mathrm{GPa}]$ & $G_{x y}[\mathrm{GPa}]$ & $\nu_{x y}[-]$ & \\
\hline CP-IM7/8552 & 90.7 & 5.3 & 0.03 & {$[18]$} \\
CP-T800/M21 & 90.8 & 5.0 & 0.03 & {$[6]$} \\
QI-T700/AR-2527 & 42.6 & 16.3 & 0.31 & {$[19]$} \\
CP-T700/ACE & 55.6 & 32.2 & 0.04 & {$[20]$} \\
\hline \hline
\end{tabular}

Table 3

Laminates investigated. 


\begin{tabular}{ccc}
\hline \hline Specimen label & $2 w[\mathrm{~mm}]$ & $a_{0}[\mathrm{~mm}]$ \\
\hline A & 10 & 3.0 \\
B & 15 & 4.5 \\
C & 20 & 6.0 \\
D & 25 & 7.5 \\
E & 30 & 9.0 \\
F & 35 & 10.5 \\
\hline
\end{tabular}

Table 4

Specimen geometry. 


\begin{tabular}{lllllll}
\cline { 2 - 6 } & $\mathrm{A}$ & $\mathrm{B}$ & $\mathrm{C}$ & $\mathrm{D}$ & $\mathrm{E}$ & $\mathrm{F}$ \\
\hline \hline CP-IM7/8552 & & $\mathrm{X}$ & $\mathrm{X}$ & $\mathrm{X}$ & $\mathrm{X}$ & \\
CP-T800/M21 & $\mathrm{X}$ & $\mathrm{X}$ & & $\mathrm{X}$ & & $\mathrm{X}$ \\
QI-T700/AR-2527 & $\mathrm{X}$ & $\mathrm{X}$ & $\mathrm{X}$ & $\mathrm{X}$ & $\mathrm{X}$ & $\mathrm{X}$ \\
CP-T700/ACE & $\mathrm{X}$ & $\mathrm{X}$ & $\mathrm{X}$ & $\mathrm{X}$ & $\mathrm{X}$ & $\mathrm{X}$ \\
\hline \hline
\end{tabular}

Table 5

Test matrix. 


\begin{tabular}{cccccccc}
\cline { 3 - 8 } & & A & B & C & D & E & F \\
\hline \hline \multirow{2}{*}{ CP-IM7/8552 } & Avg. & - & 309 & 289 & 269 & 256 & - \\
& SD & - & 9 & 16 & 11 & 10 & - \\
CP-T800/M21 & Avg. & 484 & 426 & - & 380 & - & 299 \\
& SD & 20 & 22 & - & 35 & - & 19 \\
QI-T700/AR-2527 & Avg. & 356 & 351 & 316 & 291 & 268 & 253 \\
& SD & 22 & 28 & 24 & 24 & 21 & 14 \\
CP-T700/ACE & Avg. & 339 & 325 & 323 & 299 & 277 & 271 \\
& SD & 12 & 56 & 11 & 24 & 16 & 6 \\
\hline \hline
\end{tabular}

Table $6 \overline{\overline{\text { Averase }}}$

Average and standard deviation of the ultimate remote stress, $\sigma_{u}$ (in $\mathrm{MPa}$ ). 


\begin{tabular}{lcccc} 
& $l_{f p z}[\mathrm{~mm}]$ & $\mathcal{R}_{0 s s}\left[\mathrm{~kJ} / \mathrm{m}^{2}\right]$ & $\gamma\left[\mathrm{mm}^{-1}\right]$ & $\beta[-]$ \\
\hline \hline IM7/8552 & 2.63 & 205 & 0.319 & 3.650 \\
T800/M21 & 1.14 & 283 & 0.758 & 3.527 \\
T700/AR-2527 & 1.92 & 254 & 0.4226 & 4.004 \\
\hline \hline
\end{tabular}

Table 7

Parameter of the R-curve in the longitudinal direction of the ply. 